\title{
LA GARANTÍA DE LOS ESTÁNDARES DE DERECHOS HUMANOS Y FUNDAMENTALES ANTE LAS NUEVAS AMENAZAS QUE GENERAN LOS PARTICULARES Y LOS ACTORES EXTRANJEROS*
}

\author{
MAGDALENA PÖSCHL ${ }^{1}$ \\ Catedrática de Derecho constitucional y administrativo \\ Universidad de Viena
}

\section{SUMARIO}

I. El bondadoso viejo mundo.

II. De la precisión bipolar a la confusión multipolar.

III. Del monopolio de la fuerza al poder descentralizado.

IV. Del territorio a la ausencia de fronteras.

V. ¿Un nuevo mundo lleno de peligros?

\section{EL BONDADOSO VIEJO MUNDO}

El drama clásico de los derechos fundamentales es una pieza con dos actores principales, el Estado y el ciudadano. Se ambienta en el territorio. En el primer acto, el Estado, con mucho esfuerzo, somete el territorio a su control. En el se-

* Ponencia presentada en las Jornadas de la Vereinigung der deutschen Staatsrechtslehrer celebradas en la Universidad de Düsseldorf entre el 1 y el 4 de octubre de 2014 (coponente fue Thilo Marauhn). La publicación de las ponencias y de los debates subsiguientes por parte de la editorial Walter de Gruyter hace el n. ${ }^{\circ} 74$ de la serie de las célebres VVDStRL. La autora nos ha adelantado gentilmente su texto para su traducción al castellano, realizada por Miguel Azpitarte Sánchez, Profesor titular de Derecho Constitucional en la Universidad de Granada.

1 Para superar los habituales riesgos que acechan a los ponentes en las reuniones de la Asociación de profesores de Derecho público conté con el apoyo inestimable de Hannah Berger, Lorenz Dopplinger, Rosa Duarte-Herrera, Irina Durovic, Alexandra Kunesch y Christof Rattinger, que colaboraron incansablemente en la investigación, discutieron conmigo innumerables cuestiones y controlaron las notas al pie. Espero que me disculpen por recoger solo una porción de sus aportaciones. Les estoy agradecida por sus sugerencias, su preocupación y sus muchos e inteligentes comentarios y observaciones. Iris Eisenberger, Norbert Paul Engel, Daniel Ennöckl, Clemens Jabloner, Franz Merli, Kirsten Schmalenbach, Miloš Vec y Ewald Wiederin, cada uno a su manera, me han dado importantes estímulos, han discutido conmigo incluso la concepción del trabajo y han leído críticamente el texto: a todos ellos mi agradecimiento de corazón. 
gundo, desapodera a las fuerzas intermedias y concentra en sus manos el poder absoluto. Finalmente, en el tercer acto, el todopoderoso Estado amenaza con someter al ciudadano, impotente hasta que cae en el campo de fuerza de los derechos fundamentales, que frenan al Estado y liberan al ciudadano.

Hoy, sin embargo, en la escena internacional de los derechos fundamentales reina la confusión. Junto al Estado y los ciudadanos encontramos poderosos entes privados alejados de la ciudadanía e incluso muy próximos al Estado. A su vez, en torno a los Estados aparecen figuras que se comportan institucionalmente pese a que llevan los ropajes de un particular cualquiera. También pululan en la escena organizaciones internacionales y oenegés, intercaladas entre los ciudadanos y el Estado. E incluso se cuelan en el escenario personajes que, estando integrados en Estados extranjeros, para controlar al ciudadano usan las vestimentas de los particulares, ocultando su relación con el Estado.

Sin embargo, no ha de sorprendernos que actores particulares y extranjeros desempeñen todavía un papel secundario en el drama de los derechos fundamentales, puesto que rompen la perfección de la imagen maestra, basada en tres premisas. Primera, la relación de los derechos fundamentales es bipolar, entre Estado y ciudadano. Segunda, el Estado monopoliza toda la fuerza, frente a la que nos protegen los derechos fundamentales. Y, tercera, el Estado ejerce la fuerza en su propio territorio, ¿dónde si no? Hoy estas tres premisas han de someterse a crítica.

\section{DE LA PRECISIÓN BIPOLAR A LA CONFUSIÓN MULTIPOLAR}

\section{Estado y ciudadano}

La historia sitúa en la imagen maestra al Estado como enemigo del ciudadano. Inicialmente, el individuo se integraba en diversas comunidades de dominio —el feudo, la iglesia, el burgo ${ }^{2}$ — , que, sin embargo, no tenían el mismo marco territorial, económico y social. Con el vaciamiento de estas fuerzas intermedias, el ciudadano se encuentra frente a un único actor, el Estado. En general se valora como un paso adelante ${ }^{3}$, aunque quizá este análisis teórico sea solo un reflejo deficiente de la realidad de entonces ${ }^{4}$.

2 W. ReINHARD, Geschichte der Staatsgewalt, 3. ed. 2002, 196 y ss., 211 y ss., 407; sobre «la pluralidad de los poderes de dominio» véase, por ejemplo, H. QuARITSCH, Staat und Souveränität, Vol. 1: Die Grundlagen, 1970,178 y ss.

3 Véase, por ejemplo, U. DI FABIO, «Verwaltung und Verwaltungsrecht zwischen gesellschaftlicher Selbstregulierung und staatlicher Steuerung», VVDStRL 56 (1997), 235 (253 y ss.); sobre este proceso E.-W. BÖCKENFÖRDE, Die verfassungstheoretische Unterscheidung von Staat und Gesellschaft als Bedingung der individuellen Freibeit, 1973, 10 y ss.; especialmente ilustrativo M. WEBER, Wirtschaft und Gesellschaft, 1922 (editado por J. Winckelmann, 1964, Vol. 2), 1046, para quien el Estado moderno «reúne en manos de sus rectores los medios materiales de acción, expropiándoselos al conjunto de los funcionarios estamentales que antes los tenían bajo su propio marco jurídico, y se coloca en su lugar en la posición suprema».

4 En cualquier caso, se presentan dudas desde el punto de vista de la historia global; C. A. BAYLY, Die Geburt der modernen Welt. Eine Globalgeschichte 1780-1914, 2006, 312, muestra la existencia de otras formas de 
La nítida bipolaridad entre el ciudadano y el Estado ha perdido en los últimos tiempos claridad, pues el Estado moderno no puede satisfacer con personal propio sus múltiples responsabilidades; los particulares 5 se incorporan en tal medida que es imposible tratarla como un asunto secundario ${ }^{6}$ : otorgan títulos, certifican productos, prestan servicios en nombre del Estado, reúnen datos e incluso se vigilan unos a otros ${ }^{7}$. En todas estas figuras dan la cara los particulares, pero a menudo a través de ellos habla el Estado.

El propio Estado a su vez interpreta un nuevo papel en el drama de los derechos fundamentales: ya no aparece como amenaza, sino como protector ${ }^{8}$; que, si limita libertades, lo hace también para protegernos del ejercicio de la libertad por parte de nuestros conciudadanos. De este modo, el eje de los derechos fundamentales ha girado noventa grados. Los conflictos de derechos fundamentales han dejado de ser mayoritariamente verticales para ser horizontales': el ciudadano no se enfrenta a un gran y único enemigo de los derechos fundamentales, sino a pequeños enemigos potencialmente infinitos.

Por lo demás, estos enemigos, desde hace poco, se han difuminado. Cuando alguien se queja por la vulneración del honor que provocan los vínculos automá-

estatalidad más allá del Estado centralizado del XIX: en algunos Estados el poder se dividía entre diversos grupos locales, en otros existía como contrapeso un Estado religioso y, en otros, importantes sociedades se hicieron con los medios de acción estatales, o el poder se concentraba en los jefes de los grupos originarios, y también hubo «pueblos nómadas que se apoyaron en familias, para los que el poder del Estado era tan solo el sueño de unos reyes míticos».

5 Véase al respecto, por ejemplo, F. OssenbüHL y H.-U. GaLLWAS, «Die Erfüllung von Verwaltungsaufgaben durch Private», VVDStRL 29 (1971), 137 y 211; M. SchmidT-Preuss y U. Di FabIo, «Verwaltung und Verwaltungsrecht zwischen gesellschaftlicher Selbstregulierung und staatlicher Steuerung», VVDStRL 56 (1997), 160 y 235; M. Heintzen y A. Vosskuhle, «Beteiligung Privater an der Wahrnehmung öffentlicher Aufgaben und staatliche Verantwortung», VVDStRL 62 (2003), 220 y 266; M. BuRgi, Privatisierung öffentlicher Aufgaben - Gestaltungsmöglichkeiten, Grenzen, Regelungsbedarf, Gutachten D für den 67. Deutschen Juristentag, 2008.

6 La novedad reside en la intensidad de la participación de los particulares en las actividades estatales, no en la participación misma; puesto que el Estado, tal y como ya había señalado, R. H. HerRnRitT, Grundlehren des Verwaltungsrechtes, 1921, 186, nunca ha monopolizado plenamente a la administración. Y la propia intensidad también es una novedad solo relativa, cuando la comparamos con el pasado más reciente; mirando más atrás, por ejemplo a la monarquía española del XVI, encontramos discusiones similares al actual debate sobre la privatización, véase (con más referencias) M. VEC, «Staatliche Aufgaben und private Akteure in der Rechtsgeschichte. Methodischer Etatismus als historiografisches Problem», en C. Fuchs/F. Merli/M. Pöschl/R. Sturn/E. Wiederin/A. Wimmer (ed.), Staatliche Aufgaben, private Akteure, Vol. 1: Erscheinungsformen und Effekte (en prensa).

7 Compárense los múltiples ejemplos en Di FaBio, «Selbstregulierung» (n. ${ }^{\circ}$ 3), 242 y ss.; BuRgi, Privatisierung (n. ${ }^{\circ}$ 5), 34 y ss., 41 y ss., así como las contribuciones en Fuchs/Merli/Pöschl/STuRn/WiedeRIN/WIMMER (n. ${ }^{\circ}$ 6).

8 Ya señalado por K. STERN, «Die Schutzpflichtenfunktion der Grundrechte: Eine juristische Entdeckung», DÖV 2010, 241 (244), que indica cómo el Estado ha cambiado su papel de «enemigo de los derechos fundamentales» a «amigo de los derechos fundamentales»; véase también K. GÜNTHER, «Menschenrechte zwischen Staaten und Dritten: Vom vertikalen zum horizontalen Verständnis der Menschenrechte», en N. Deitelhoff/J. Steffek (coord.), Was bleibt vom Staat? Demokratie, Recht und Verfassung im globalen Zeitalter, 2009, 259 (261 y ss., 271 y ss.), que nos remite a la ambivalencia y los riesgos de este desarrollo.

9 Günther, en Deitelhoff/Steffek (n. ${ }^{\circ}$ 8), 261 y ss., 266 y ss. 
ticos que establece un motor de búsqueda, ¿se refiere a las búsquedas previas realizadas en la red o simplemente al algoritmo que las organiza? ${ }^{10}$, ¿y cómo defendernos frente a la red o un algoritmo? Así, la antigua precisión de la relación bipolar entre el ciudadano y el Estado deja paso a la confusión multipolar, donde los enemigos de los derechos fundamentales parecen esfumarse.

\section{La administración pública desempeñada por particulares}

La doctrina ha intentado en primer lugar encarrilar estos nuevos fenómenos con las viejas categorías. Así las cosas, en Alemania, Austria y Suiza existe consenso respecto a la administración pública desempeñada por particulares: si el Estado otorga a alguien poder público, esta persona se convierte en Estado y queda vinculada a los derechos fundamentales ${ }^{11}$. Perspectiva que, en definitiva, se apoya sobre la idea de que el poder público corresponde en exclusiva al Estado: ¿a quién si no?, ¿cómo reconoceríamos en otro caso al Estado? ${ }^{12}$

Sin embargo, sorprendentemente, no nos queda del todo claro qué es en verdad el poder público. Se discute si lo ostentan aquellos organismos a los que se les ha concedido poder para establecer estándares vinculantes ${ }^{13}$, y la misma duda se tiene para las instituciones con poderes certificativos ${ }^{14}$, para los nota-

10 Argumentos similares sirvieron al Tribunal Superior de Colonia para desestimar una demanda que reclamaba porque el buscador Google ligaba de modo automático el nombre del demandante con los términos «cienciología» y «estafa», aunque no tenía relación alguna con la cienciología y no se le había imputado jamás una estafa, pero véase también la sentencia del Tribunal Supremo (BGH) de 14.5.2013, Az. VI ZR 269/12, DuD 2013, 663, que rechaza la interpretación del Tribunal Superior de Colonia, así como la sentencia final de éste de 8.4.2014, 15 U 199/11.

11 Con ulteriores referencias en cada caso, véase para Alemania W. Graf VitzThum en D. Merten/H.-J. Papier (dir.), Handbuch der Grundrechte in Deutschland und Europa, Vol. II, 2006, § 48 ap. 38 ; H. Maurer, Allgemeines Verwaltungsrecht, 18. ed. 2011, § 23 ap. 58; H. Dreier en H. Dreier (dir.), Grundgesetz Kommentar, Vol. I, 3. ed. 2013, art. 1.3 ap. 39; para Austria W. BerkA, Die Grundrechte, 1999, ap. 194; para Suiza G. MülleR, «Schutzwirkung der Grundrechte», en Merten/Papier, cit., Vo. VII/2, 2007, § 204 ap. 17; P. Tschannen, Staatsrecht der Schweizerischen Eidgenossenschaft, 3. ed. 2011, § 7 ap. 42 . En tanto no ejerza actuaciones de autoridad, el concesionario se mantiene como un simple privado titular de derechos fundamentales, H. J. Wolff/O. BACHOF/R. STOBER, Verwaltungsrecht, Bd. III, 5. ed. 2004, §90 VII 2 ap. 47.

12 Véase K. Vogel, Öffentliche Wirtschaftseinheiten in privater Hand, 1959, 80 y ss., para quien el único derecho imputable de modo exclusivo al Estado es el poder de configurar unilateralmente relaciones jurídicas.

13 Véase Vosskuhle, «Beteiligung» (n. ${ }^{\circ}$ ), 294 y ss., para quien la estandarización no admite una clasificación inequívoca; en contra de considerarla como atribución de poder público Dreier, en Dreier (n. ${ }^{\circ} 11$ ), art. 1.3 ap. 43 .

14 Contra su consideración como cesión de poder público BuRgI, Privatisierung (n. ${ }^{\circ}$ 5), 45 ; F. MERLI, «Bewertung durch Private», en Fuchs/Merli/Pöschl/Sturn/Wiederin/Wimmer (n. ${ }^{\circ}$ 6); a favor por ejemplo F. Reimer, Qualitätssicherung, 2010, 286 y ss.; como un derecho mixto de nuevo cuño G. Dimitropoulos, Zertifizierung und Akkreditierung im Internationalen Verwaltungsverbund. Internationale Verbundverwaltung und gesellschaftliche Administration, 2012, 126 y ss., 251 y ss., 288 y ss.; véase también VfSlg. 19.728/2012, en el que la certificación de los cursos de alemán para inmigrantes se considera «una actividad de poder público», al respecto M. HoLOubeK, «Handlungsformen, Legalitätsprinzip und Verwaltungsgerichtsbarkeit», FS Ra- 
rios $^{15}$ o para los particulares que vigilan el medioambiente ${ }^{16} \mathrm{u}$ ofrecen alojamiento provisional a los solicitantes de asilo ${ }^{17}$. Ninguno de ellos ejerce coacción física o imparte órdenes. En sentido estricto no suponen concesiones, y sin embargo probamos a calificarlas como tales porque percibimos en ellas un riesgo para los derechos fundamentales que no surge solo de la relación de sujeción ${ }^{18}$.

Así, hoy existe la tendencia a conceptuar de manera amplia la vinculación a los derechos fundamentales de los particulares que ejercen funciones de administración pública, siguiendo distintos caminos según cada cultura jurídica. En Suiza han puesto las cartas sobre la mesa. Su Constitución dispone expresamente que está vinculado a los derechos fundamentales todo aquel que realiza tareas estatales (art. 35.2) —aquí encajaría el concesionario, pero no solo él ${ }^{19}$ —. En Alemania se alcanza un resultado similar, extendiendo el concepto de concesionario al cumplimiento de tareas estatales sin servirse del poder público ${ }^{20}$. Y del mismo modo

schauer, 2013, 181 (189 y ss.); del mismo autor «Das «Zertifizierungsrechtsverhältnis» — Überlegungen zu «Staat» und «Privat» im Wirtschaftsrecht», FS Stolzlechner, 2013, 259 (270, n. $\left.{ }^{\circ} 43\right)$.

15 Se posiciona a favor de la concesión M. BurGI, «Aufgabenübertragungen auf den Notar im Lichte der Allgemeinen Privatisierungsdogmatik», en N. Preuß (dir.), Aufgabenübertragung auf Notare, 2011, 31 (38), con referencias a la posición contraria

16 Para los problemas de clasificación véase VosskuHLe, «Beteiligung» (n. ${ }^{\circ}$ 5), 294 y ss.

17 Concesionarios en Suiza, BGE 133 I 49 X. En Austria la clasificación es confusa: los particulares que ofrecen alojamiento no están autorizados por ley para ejercer poder público, pero los Länder les obligan en parte mediante contrato a redactar reglamentos de organización doméstica que reciben la conformidad de la autoridad competente, tarea que se acerca en gran medida a una competencia de ordenación. A su vez, estos reglamentos son suscritos por los solicitantes de asilo, lo que de nuevo indica que su vinculatoriedad está unida a una manifestación de autonomía privada; respecto a esta división de funciones entre el Estado y los particulares véase por ejemplo A. KöNIG/S. RosenBERGER, «Desintegration, Dezentralität, Disziplinierung: Grundversorgung im Bundesländervergleich», en S. Rosenberger (dir.), Asylpolitik in Österreich. Unterbringung im Fokus, 2010, 273 y ss.; respecto a los reglamentos de organización doméstica, 282 y ss. y, por ejemplo, M. Bergthaller/H. Moser, «Parallel zur Gesellschaft? Eine Untersuchung zur Grundversorgung von AsylwerberInnen in Oberösterreich», en S. Rosenberger, cit., 203 (208 y ss.).

18 Así, por ejemplo, las autoridades de certificación ejercen «coacción voluntaria», pues sus valoraciones de conformidad son prácticamente irrenunciables para los actores económicos, véase BuRGI, Privatisierung (n. ${ }^{\circ}$ 5), 43. Las fuerzas de seguridad privada podrían mediante las patrullas mixtas participar de modo "parasitario» en las fuerzas de seguridad del Estado, tal y como ha señalado S. Rixen, «Vom Polizeirecht über das Gewerberecht zurück zum Polizeyrecht?», DVBl 2007, 221 (226). Las relaciones de poder fáctico surgen cuando un operador ha de mostrar sus secretos comerciales a la institución certificante que a su vez trabaja para la competencia en el sector o que cobra en función del tiempo empleado, por lo que está interesada en un examen a fondo, Di FABIO, «Selbstregulierung» (n. ${ }^{\circ}$ 3), 257. Pagar a los particulares con honorarios fijos no resuelve los problemas de manera automática, sino que incluso pueden provocarlos, como se ha demostrado en Austria para los asuntos relativos al acogimiento de solicitantes de asilo, en gran medida a cargo de particulares. El hecho de que los Länder costeen un importe fijo por solicitante de asilo hace que ganen más aquellos que peor alojamiento ofrecen. Esto podría explicar por qué en 2013 aproximadamente un tercio se encontraba en una situación inadmisible: véase el dosier Wo man mit „Schwein! grüßt. Wie Bebörden dabei versagen, Asylwerber menschenwürdig zu beherbergen, Falter 47/13; la mala situación ya había sido señalada en el estudio de Rosenberger, Asylpolitik (n. ${ }^{\circ} 17$ ).

19 Más en detalle M. SchefER, «Grundrechtliche Schutzpflichten und die Auslagerung staatlicher Aufgaben», AJP/PJA 10/2002, 1131 (1139 y ss.).

20 B. Schmidt aм Busch, «Die Beleihung: Ein Rechtsinstitut im Wandel», DÖV 2007, 533 (535). Desde otras perspectivas se aboga por comprender también como concesión la «traslación de la responsabili- 
proceden los tribunales civiles austriacos ${ }^{21}$; el Derecho público, en los casos comprometidos, se pregunta si el particular realiza tareas públicas; de ser así, se presume que el legislador le ha dado potestades públicas ${ }^{22}$. Finalmente, en caso de que las ideas de potestades públicas y tareas públicas no ayuden, entonces se utiliza un tercer criterio, el de la intervención estatal: cuando el Estado influye de manera intensa sobre la acción de los particulares (por ejemplo, mediante la elección, las instrucciones o la revocación), ésta le será imputada, y quedará así vinculada a los derechos fundamentales ${ }^{23}$.

La imprecisión de estos tres criterios — potestad pública, tareas públicas e intervención - es evidente ${ }^{24}$. En esta debilidad seguramente reside su fuerza, pues permite comprender lo novedoso en el Estado, cuya forma e instrumentos de domino son siempre cambiantes. Es más, todavía no sabemos bien en qué consiste el Estado, más allá de ser actor principal en el drama de los derechos fundamentales. Aunque tampoco lo teníamos claro en el pasado, pese a contar

dad para realizar tareas públicas, dando pie a una supremacía en principio fáctica, pero sustentada por las normas», Di Fabio, "Selbstregulierung» (n. $\left.{ }^{\circ} 3\right), 273$. Sin embargo, no se ha impuesto la teoría pura de las tareas estatales de U. STEINER, Öffentliche Verwaltung durch Private, 1975, 46 y ss., para la que bastaría que un particular realizase tareas estatales en sentido material, véase M. BuRGI, «Der Beliehene - ein Klassiker im modernen Verwaltungsrecht», FS Maurer, 2001, 581 (585 n. ${ }^{\circ} 33$ ). Con razón señala STEINER, 47 y ss., sin embargo, que una actuación de esta naturaleza solo se identifica como estatal a través de la tarea que con ella se realiza.

21 Esto tiene especial eficacia en el ámbito de la responsabilidad personal de los funcionarios, W. SCHRAGEL, Kommentar zum Amtshaftungsgesetz, 3. ed. 2003, § 1 ap. 80.

22 Ejemplos tomados de la amplia bibliografía ofrece M. Pöschl, «Private Verwalter als Problem des Allgemeinen Verwaltungsrechts», FS Mayer, 2011, 515 (526 n. ${ }^{\circ}$ 73). Cuando de la transferencia de tareas públicas se deducen potestades públicas se habla significativamente de «tareas del poder público» o «tareas soberanas», por ejemplo en la n. ${ }^{\circ} 73$ de VfSlg. 19.728/2012. Respecto a las fluidas transiciones entre poder público y tareas públicas véase Di FABIO, «Selbstregulierung» (n. ${ }^{\circ}$ 3), 264, para quien «el Estado, que mediante su conformación del ordenamiento hace poderosas de hecho a algunas organizaciones y les traslada la realización de las tareas públicas, impregna el orden privado con elementos de poder público». Por lo demás, se apela también al criterio de las tareas públicas para asegurar la vinculación a los derechos fundamentales; así, por ejemplo, la doctrina austriaca considera que la actuación económica privada de las corporaciones territoriales está vinculada a los derechos fundamentales cuando realizan tareas públicas, pero no cuando lo hagan con fines lucrativos (BERKA, Grundrechte [n. $\left.{ }^{\circ} 11\right]$, ap. 173 y ss.; T. ÖHLINGER/H. EBERHARD, Verfassungsrecht, 10. ed. 2014, ap. 705). Lo mismo se puede decir conforme al art. 35.2 BV para Suiza (BGE 127 I 84, 90); R. RHINOw/M. SCHEFER, Schweizerisches Verfassungsrecht, 2. ed. 2009, ap. 1155; R. KIENER/W. KäLIN, Grundrechte, 2. ed. 2013, 46 y ss.). Las personas jurídicas de derecho público están plenamenta vinculadas a los derechos fundamentales, tal y como afirma el CEDH, cuando ejercen tareas de administracion pública; el ejercicio de potestades públicas se considera aquí como el criterio más importante, C. Grabenwarter/K. Pabel, Europäische Menschenrechtskonvention, 5. ed. 2012, $\$ 13$ ap. 13 .

23 Respecto de Alemania véase Burgi, Der Beliehene (n. $\left.{ }^{\circ} 20\right)$, 589, para quien el establecimiento de competencias de vigilancia estatal es un punto de referencia en favor de la concesión; en Austria, por ejemplo, H.-P. RILL, «Zum Verwaltungsbegriff», FS Antoniolli, 1979, 35 (55), quien considera que una especial vinculación organizativa con una corporación territorial es indicativa de una concesión; en este sentido M. KrajCSIR, Staatliche Hoheitsverwaltung durch Private, 1999, 72; para Suiza SCHEFER, «Schutzpflichten» (n. ${ }^{\circ}$ 19), 1133, 1141 y ss., para quien, ante la falta de claridad respecto a la existencia de una tarea pública, es determinante saber en qué medida el Estado puede influir sobre esa actuación.

24 En detalle Pöschl, «Private Verwalter» (n. $\left.{ }^{\circ} 22\right), 524$ y ss. 
con definiciones canónicas, como la de G. Jellinek ${ }^{25}$; los tres criterios mencionados para distinguir entre Estado y ciudadanos están ya apuntados desde O. Mayer, con un peso respectivo diferente ${ }^{26}$. Sea como fuere, estamos obligados a reaccionar frente a las formas típicas de dominio: si el Estado ya no dirige solo a través de la coacción, sino también con la «cooperación» ${ }^{27}$, ajustamos el concepto de Estado y situamos en un lugar prioritario las tareas públicas. Y por ello conceptualizamos al Estado más allá del monopolio de la fuerza, atendiendo a las nuevas amenazas de los derechos fundamentales que surgen en ese campo desde los actores privados.

\section{El particular que perturba los derechos fundamentales}

Aceptado el sometimiento a los derechos fundamentales de los entes híbridos público-privados, hemos de preguntarnos qué ocurre con los particulares en sentido estricto, que también pueden afectar a la libertad. Hoy, en Alemania, Austria y Suiza, la mayoría de la doctrina niega que los particulares estén sometidos de manera directa a los derechos fundamentales ${ }^{28}$. Conclusión convincente a la luz de los catálogos de derechos fundamentales recogidos en cada uno de los tres ordenamientos, que reservan al legislador la determinación de las condiciones bajo las que cabe intervenir sobre los derechos fundamentales. Es evidente que la autoridad administrativa está sujeta a tales disposiciones legislativas, y

25 G. JellineK, Allgemeine Staatslehre, 3. ed. 1914; respecto a este y otros conceptos centrales de Estado, C. Möllers, Staat als Argument, 2. ed. 2011, 12 y ss.

26 Para un análisis del desarrollo de estos criterios PösCHL, «Private Verwalter» (n. $\left.{ }^{\circ} 22\right), 517$ y ss.

27 Conceptualizó el «Estado cooperativo» E.-H. RiTTER, «Der kooperative Staat. Bemerkungen zum Verhältnis von Staat und Wirtschaft», AöR 104, 1979, 389; para el desarrollo ulterior, por ejemplo, G. F. SCHuPpert, Verwaltungswissenschaft, 2000, 115 y ss.

28 Para el caso alemán véase H.-J. PAPIER, «Drittwirkung», en Merten/Papier (n. $\left.{ }^{\circ} 11\right)$, Vol. II, 2006, $\S 55$ ap. 24; S. Müller-Franken, «Bindung Privater an Grundrechte? Zur Wirkung der Grundrechte auf Privatrechtsbeziehungen», FS Bethge, 2009, 223; H. Dreier, en Dreier (n. ${ }^{\circ} 11$ ), prefacio al art. 1, ap. 98; para Austria Berka, Grundrechte (n. ${ }^{\circ}$ 11), ap. 228 y ss.; J. HengStschläGer/D. Leeb, Grundrechte, 2. ed. 2013, ap. 1/74; E. SCHUlEv-STEINDL, «Drittwirkung und Fiskalgeltung», en D. Merten/H.-J. Papier/G. Kucsko-Stadlmayer (dir.), Handbuch der Grundrechte in Deutschland und Europa, Bd. VII/1, 2. ed. 2014, \$ 6 ap. 7 y ss. En Suiza la vinculación de los derechos fundamentales entre particulares se encuentra prevista de forma expresa y formulada de manera neutral en el art. 35. 1 y $3 \mathrm{BV}: 1$. «Los derechos fundamentales deben tener eficacia en todo el ordenamiento»; 3. «Las autoridades deben garantizar que los derechos fundamentales, en la medida que les corresponda, también vinculan a los particulares»; pero en la mayoría de la doctrina se interpreta como una vinculación mediata: W. Haller/A. KöLz/T. Gächter, Allgemeines Staatsrecht, 4. ed. 2008, 318 y ss.; Rhinow/SCHefer, Verfassungsrecht (n. ${ }^{\circ} 22$ ), ap. 1171; Tschannen, Staatsrecht (n..$\left.^{\circ} 11\right), \S 7$ ap. 63; KIENER/KäLIN, Grundrechte (n. $\left.{ }^{\circ} 29\right)$, 53. Sin embargo, en parte se acepta que los derechos fundamentales tienen una aplicación directa cuando no resulta suficiente para dotarles de eficacia una interpretación conforme de la legislación, véase R. J. Schweizer, en B. Ehrenzeller/B. Schindler/R. J. Schweizer/K. A. Vallender (dir.), Die schweizerische Bundesverfassung, 3. ed. 2014, art. 35 BV ap. 59 y ss. En el resto de países europeos, mayoritariamente se acepta, pero no siempre, una eficacia mediata, véase A. SEIFERT, «Die horizontale Wirkung von Grundrechten», EuZW 2011, 696 (697), véase también la n. 42. 
también lo ha de estar la judicial ${ }^{29}$ : para intervenir sobre los derechos fundamentales necesitan no sólo apoyarse en otros derechos fundamentales, sino en todo caso habilitación legislativa. A través de esta mediación de la ley ordinaria, tales derechos despliegan su eficacia también entre los particulares.

La doctrina mayoritaria considera hoy que el Estado no solo está autorizado sino que también puede estar obligado a proteger a los ciudadanos, sobre todo a través de la ley, frente a las injerencias en los derechos fundamentales procedentes de otros ciudadanos ${ }^{30}$. Sin duda, hay divergencia de opiniones sobre el éxito de esta doctrina del deber de protección ${ }^{31}$, aunque en cualquier caso nos ha hecho conscientes de que los derechos fundamentales, desde el principio, nos protegen

29 G. Hermes, «Verfassungsrecht und einfaches Recht - Verfassungsgerichtsbarkeit und Fachgerichtsbarkeit», VVDStRL 61 (2002), 119 (136 y ss.), con razón critica que la doctrina considera evidente la vinculación de la Administración a la ley, mientras degrada los excesos judiciales en la interpretación de la ley a simple un problema metodológico.

30 Para Alemania Dreier, en Dreier (n. $\left.{ }^{\circ} 11\right)$, prefacio al art. 1, ap. 101 y ss; C. Calliess, «Schutzpflichten», en Merten/Papier (n. $\left.{ }^{\circ} 11\right)$, Vol. II, 2006, § 44 ap. 4; para Austria M. HoloubeK, Grundrechtliche Gewährleistungspflichten, 1997, 146 y ss. et passim; G. KuCsKo-STAdLmayer, «Die allgemeinen Strukturen der Grundrechte», en Merten/Papier/Kucsko-Stadlmayer (n. ${ }^{\circ}$ 28), Vol. VII/1, 2. ed. 2014 , $\$ 3$ ap. 56 y ss.; para Suiza Müller, «Schutzwirkung» (n. $\left.{ }^{\circ} 11\right), \S 204$ ap. 4; KIENER/KäLIN, Grundrechte (n. $\left.{ }^{\circ} 22\right), 37$ y ss.

31 Mi opinión sobre este resultado es algo menos generosa que la fama que acompaña a la doctrina del deber de protección. En primer lugar, muchas leyes de garantía existirían también sin el deber de protección y en gran medida son más antiguas que los derechos fundamentales que defienden, como ocurre con las disposiciones mencionadas por STERN, «Schutzpflichtenfunktion» (n. $\left.{ }^{\circ} 8\right), 246$, en el ámbito del derecho laboral, del contrato de arrendamiento y en la parte general del derecho de contratación. Por otro lado, llama la atención que las reivindicaciones de nuevas leyes de garantía naufraguen en el amplio margen de discrecionalidad que al respecto se reconoce al legislador, véanse igualmente en STERN, «Schutzpflichtenfunktion» ( . $\left.^{\circ} 8\right)$, 245, 247, los supuestos de la contaminación medioambiental, el depósito de armas químicas y los abusos de los grandes bancos y empresas; pero en el ámbito del CEDH se constatan más violaciones del deber de protección, véase H. KRIEGER «Positive Verpflichtungen unter der EMRK: Unentbehrliches Element einer gemein-europäischen Grundrechtsdogmatik, leeres Versprechen oder Grenze der Justiziabilität?», Zä̈RV 2014, 187 (190). Más dudas que ese alcance a veces limitado provoca el abuso argumentativo de las obligaciones de protección o su empleo irreflexivo para justificar más fácilmente intervenciones sobre los derechos de libertad. Esto ocurre, por ejemplo, cuando algunas intervenciones sobre los derechos de libertad se conciben como omisión de un deber de protección y así se consideran justificadas gracias al amplio margen de discrecionalidad del legislador (por ejemplo infra, notas 169 y 181). Ocurre también cuando los fines estatales clásicos se reformulan como deberes de protección para hacer así más populares las intervenciones sobre los derechos de libertad, como sucedió por ejemplo con las amplias medidas de vigilancia resultantes de la persecución del terrorismo tras los atentados del 11 de septiembre de 2001, presentadas esencialmente como medidas de protección de los derechos fundamentales a la vida, la salud y la propiedad. Se da incluso un abuso interpretativo cuando limitaciones de la libertad que exigirían justificación se convierten en medidas necesarias para la protección de los derechos fundamentales, dándoles de ese modo inmunidad frente a la crítica; se pueden citar como ejemplos la prohibición de investigación apoyada sobre la dignidad humana (C. KOPETZKI, «Zur Lage der embryonalen Stammzellen in Österreich», FS Deutsch, 2009, 297), pero también la reciente pretensión de criminalizar la circuncisión por motivos religiosos, cuya práctica era aceptada desde hace siglos (con razón en contra de ello C. JABLONER, «Shylocks Recht», FS Schlink, 2014, 173 [181 y ss. en especial 184 y ss.]). Para evitar un incremento del abuso, los problemas relativos a los deberes de protección debieran tratarse dogmáticamente, en la medida de lo posible, desde la perspectiva de la garantía de no intervención en la libertad individual, véase P. SzczeKalla, Die sogenannten grundrechtlichen Schutzpflichten im deutschen und europäischen Recht, 2002, 404 y ss. 
frente al Estado y además transforman de modo fundamental la sociedad ${ }^{32}$. Esto se ve con claridad cuando las Cartas de derechos fundamentales suprimen la servidumbre y la sumisión ${ }^{33}$, prohíben la esclavitud ${ }^{34}$ y excluyen todo tipo de privilegios en razón del nacimiento o la confesión religiosa ${ }^{35}$ : tales garantías no protegen frente al Estado, sino que se aprovechan de su poder para exigirle que destruya relaciones sociales de dominio; el impulso de estos derechos «no fue antiestatal, sino antiestamental» ${ }^{36}$. Las fuerzas intermedias, que han perdido privilegios y poder en virtud de los derechos fundamentales, estaban vinculadas al Estado o eran parte de él, el cual a su vez necesitaba de sus capacidades específicas o su proximidad física, en especial en el control del territorio. Solo cuando el Estado controló con su propio personal el último rincón, pudieron él y la sociedad liberarse de los intermediarios ${ }^{37}$. Tengamos en cuenta que un Estado que depende de los particulares en las cuestiones centrales de su dominio político puede quedar bloqueado en la protección del interés general.

Esto nos lleva a preguntarnos qué ocurre cuando el legislador incumple su obligación de protección. En la práctica, los tribunales resuelven muchos problemas mediante las cláusulas generales del Derecho privado ${ }^{38}$, que remiten a la moral pública o a figuras similares, de suerte que quedan abiertas a su determinación mediante los derechos fundamentales ${ }^{39}$. Si de este modo no se logra la protección del derecho fundamental, los tribunales directamente utilizan la creación jurídica ${ }^{40}$; se trata, aunque no se diga de modo expreso, de una aplicación

32 Para Alemania, con muchas referencias bibliográficas, H. DreIER, Dimensionen der Grundrechte, 1993, en especial 33, donde sostiene que atribuir a los derechos fundamentales simplemente una función defensiva supone un «brutal reduccionismo» que ha de rechazarse. Para Austria en este sentido F. LEHNE, «Grundrechte achten und schützen? 1862 und 1867», JBl 1986, 341 u 424; para Suiza por ejemplo M. Schefer, Die Kerngehalte von Grundrechten: Geltung, Dogmatik, inhaltiche Ausgestaltung, 2001, 246 y ss.

33 Véanse por ejemplo para Alemania $§ 3$ Verfassung des Königreichs Bayern 1808, § 166 Paulskirchenverfassung 1849; para Austria § 26 Märzverfassung 1849, Sylvesterpatent 1851, art. 7 StGG; para Suiza art. 4 Bundesverfassung 1848, art. 4 Bundesverfassung 1974.

34 Para Austria § 26 Märzverfassung 1849; también art. 4 CEDH.

35 Para Alemania $\$ 137$ Paulskirchenverfassung 1849, art. 4 y art. 12 Preußische Verfassung 1850, art. 3.3 GG; para Austria art. 2 y art. 14 StGG, art. 7.1 B-VG; para Suiza $§ 6$ Staatsgrundgesetz Helvetiens 1802 , art. 3 Mediationsverfassung 1803, art. 4 Bundesverfassung 1848, art. 4 Bundesverfassung 1974 , art. $8.2 \mathrm{BV}$.

36 Dreier, Dimensionen (n. $\left.{ }^{\circ} 32\right), 29$.

37 Reinhard, Staatsgewalt (n. ${ }^{\circ}$ 2), 183 y ss., 196 y ss., 305, 317 y ss. En una nueva perspectiva de la historia global se hace evidente que tales explicaciones tienen un lado eurocéntrico y por tanto debilidades y puntos ciegos. En definitiva, los imperios siempre han gobernado de otro modo, véase VEC, «Staatliche Aufgaben», en Fuchs/Merli/Pöschl/Sturn/Wiederin/Wimmer (n. ${ }^{\circ}$ 6).

38 En Alemania especialmente $\$ \S 138,242,826$ BGB; en Austria en especial $\$ \S 16,879$ y 1295 ABGB, en Suiza en especial art. 2 ZGB.

39 Al ser estas cláusulas «piezas de legislación que quedan abiertas» (J. W. HedemanN, Die Flucht in die Generalklauseln, 1933, 58), los derechos fundamentales se aplican sin concreción legal; pero el legislador los ha aceptado introduciendo una generosa norma de remisión.

40 En Suiza se apoyan en el art. 2. 2 ZGB, de acuerdo con el cual «no recibe protección jurídica [...] ningún abuso palmario de un derecho»; se ve en ello una habilitación para la corrección de la ley, H. HAUS- 
directa de los derechos fundamentales ${ }^{41}$. En cualquier caso, la eficacia directa no tiene un uso prioritario, sino que parte del banquillo de los suplentes; entra en juego si falla la protección legislativa ${ }^{42}$.

Los tribunales ya compensaban la ausencia de protección legislativa cuando todavía no se hablaba de eficacia directa o de obligaciones de protección. Un ejemplo sería el régimen jurídico del deber de contratación, que en Alemania, Austria y Suiza se desarrolló judicialmente ${ }^{43}$. Otro sería el principio de igualdad laboral, que la jurisdicción civil alemana y austriaca «descubrieron» con el aplauso de la doctrina, que especuló durante décadas sobre la norma de la que habría

HeEr/R. Aebi-Müller, en H. Hausheer/H. P. Walter (dir.), Berner Kommentar 2012, art. 2 ZGB ap. 16 y ss.; en especial sobre la corrección de la ley conforme a los derechos fundamentales por ejemplo SCHEFER, «Schutzpflichten» (n. $\left.{ }^{\circ} 19\right), 1137$ n. ${ }^{\circ} 52$.

41 Se considera que el fundamento legislativo en este caso es el propio derecho fundamental (SzczEKALla, Schutzpflichten [n. ${ }^{\circ} 31$ ], 162); claramente en contra TsCHANNEN, Staatsrecht (n. ${ }^{\circ} 11$ ), $\$ 7$ ap. $73:$ :La doctrina de los deberes de protección derivada de los derechos fundamentales conlleva el riesgo [...] de conformarse con los derechos fundamentales de unos como soporte para la intervención sobre los derechos de otros. De este modo se arrumba el principio de legalidad en el marco de los derechos fundamentales, y, lo que es peor, apelando a los propios derechos fundamentales». Existe una alternativa a este camino de creación jurídica -aunque no siempre resolverá satisfactoriamente el conflicto de origen- cuando los tribunales constitucionales estén autorizados para exigir la actuación del legislador o para declarar la inconstitucionalidad de la omisión legislativa, para Alemania véase J. DietLein, Die Lebre von den grundrechtlichen Schutzpflichten, 2. ed. 2005, 180 y ss.; K. SCHLAich/S. Korioth, Das Bundesverfassungsgericht, 9. ed. 2012, ap. 394 y ss. Véase también el art. 41 del CEDH, según el cual el TEDH puede constatar violaciones de la Convención, y por tanto también de los deberes de protección, ofrece numerosos ejemplos H. KRIEGER, «Positive Verpflichtungen» (n. $\left.{ }^{\circ} 31\right), 190,198$.

42 De este modo, la praxis se acerca a la situación de los Estados en los que los particulares se consideran directamente vinculados por los derechos fundamentales en tanto que el legislador ordinario no asuma su tarea de protección, véase para Brasil I. W. SARLET, «Die Einwirkung der Grundrechte auf das brasilianische Privatrecht», en Neuner (dir.), Grundrechte und Privatrecht aus rechtsvergleichender Sicht, 2007, 81 (en especial 96 y ss.). En términos similares, en Portugal se defiende que los derechos fundamentales se aplican mediante normas jurídico-privadas en las relaciones entre particulares, pero si un tribunal no encuentra una norma adecuada, debe aplicar directamente el derecho fundamental, P. M. PinTo, «Die Einwirkung der Grundrechte auf das portugiesische Privatrecht», también en Neuner, 105 (112 y ss.); también en España, J. M. Bilbao Ubillos, «Die Einwirkung der Grundrechte auf das spanische Privatrecht», en Neuner, 119 (139 y ss.). Distinguir entre vinculación de los derechos fundamentales exclusiva del Estado, directa para los particulares e indirecta solo cabe desde una perspectiva teórica, pues en la práctica producen resultados similares, véase en un análisis comparado C. O'Cinneide/M. STELzer, «Horizontal effect/state action», en M. Tushnet/T. Fleiner/C. Saunders (dir.) Routledge Handbook of Constitutional Law, 2012, 177 y ss.; igualmente S. PERner, Grundfreibeiten, Grundrechte-Charta und Privatrecht, 2013, 162 y ss.

43 Particularmente independiente es tal jurisprudencia en Austria, donde el deber de contratar se apoya en el $\S 879$ ABGB, justo la prescripción que establece la nulidad de los contratos contrarios a las buenas costumbres, véase la sentencia OGH 16.9.1971, 1 Ob 227/71; con respecto a esta jurisprudencia L. KhakZadeh-Leiler, Die Grundrechte in der Judikatur des Obersten Gerichtshofs, 2011, 127 y ss. En Alemania, la contratación forzosa se deduce del $\S 826$ BGB, pero también a veces directamente del principio de igualdad: J. Busche, en F. J. Säcker/R. Rixecker (dir.), Münchener Kommentar zum Bürgerlichen Gesetzbuch, 6. ed. 2012, Vor $\S 145$ ap. 20 y ss. En Suiza, la doctrina apoya la contratación forzosa en el principio de igualdad (H. Merz, Vertrag und Vertragsschluss, 2. ed. 1992, ap. 287) y la jurisprudencia en la prohibición de daños contrarios a las buenas costumbres del art. 41 OR (C. Müller, en A. Furrer/A. Schnyder [coord.], Handkommentar zum Schweizer Privatrecht, Vol. IV, 2. ed. 2012, art. 41 OR ap. 56). 
de deducirse este principio ${ }^{44}$, hasta que por ejemplo en Austria acabó reconociéndose legislativamente ${ }^{45}$.

Con el tiempo, el legislador suele codificar, a veces con variantes, el desarrollo judicial de los derechos fundamentales. Por ejemplo, el de igualdad laboral incluso ha ganado en densidad gracias al derecho europeo antidiscriminatorio ${ }^{46}$. Ocasionalmente las Constituciones regulan expresamente la eficacia directa, como es el caso de la igualdad salarial del hombre y la mujer ${ }^{47}$ o el derecho de sindicación ${ }^{48}$. En Austria, el derecho fundamental a la protección de datos vincula a los particulares desde $1980^{49}$, alegándose ya entonces que podía surgir del ámbito privado un gran hermano orwelliano capaz «de manipularnos y estrangular la libertad» ${ }^{50}$. También hoy el derecho europeo de la protección de datos, que atribuye derechos frente al Estado y frente a los particulares, quiere protegernos frente al poder de la información ${ }^{51}$.

En conjunto, se ha relativizado la bipolaridad de los derechos fundamentales, por más que estos existan esencialmente entre el Estado y los ciudadanos. Pero a través de la judicatura, de las Constituciones nacionales y del derecho europeo

44 Para Alemania H. Wiedemann, Die Gleichbehandlungsgebote im Arbeitsrecht, 2001, 10; para Austria M. PösCHL, «Verfassungsrechtliche Gleichheit, arbeitsrechtliche Gleichbehandlung, unionsrechtliche Antidiskriminierung», DRdA 2013, 467 (472 y ss.). En Suiza se ha escogido el camino contrario: una vez que la doctrina (por ejempolo T. GEISER, «Gibt es ein Gleichbehandlungsgebot im schweizerischen Arbeitsrecht?», FS Rebbinder, 2002, 37 y ss.; K. P̈̈RLI, Vertragsfreibeit, Gleichbehandlung und Diskriminierung im privatrechtlichen Arbeitsverbältnis, 2009, ap. 1443 y ss.) ha alcanzado un amplio consenso sobre el fundamento del que derivar el principio de igualdad laboral, entonces la jurisprudencia ha pasado a aplicar paulatinamente el principio, BGE 129 III 276 (281 y ss.).

$45 \S 18$ Betriebspensionsgesetz, BGB1. 1990/282. Otros muchos ejemplos relativos a la creación judicial de derecho que se convierte en eficacia directa de los derechos fundamentales en H.-G. vON DüCKER, «Der Richter als Ersatzgesetzgeber», FS Maurer, 2001, 49 (55 y ss.).

46 En parte, el principio de igualdad de trato también llena lagunas que deja el derecho antidiscriminatorio, véase para Austria Pöschl, «Gleichheit» (n. $\left.{ }^{\circ} 44\right), 481$ y sigs. Ocasionalmente, las prohibiciones de discriminación previstas allí para los particulares son incluso más estrictas que para el Estado, de manera que, por ejemplo, el empleador tiene una especial carga argumentativa cuando perjudica a un trabajador por su edad - un rasgo que el Estado puede utilizar y de hecho utiliza para tratar de modo distinto sin justificación específica, M. PöscHL, «Altersdiskriminierung und Verfassung», en WiR — Studiengesellschaft für Wirtschaft und Recht (dir.), Alter und Recht, 2012, 47 (48, 51).

47 Art. 8.3 p. 3 BV; la igualdad salarial rige en la Unión Europea conforme al art. 157 TFUE y vincula también a los particulares de acuerdo con la jurisprudencia del Tribunal de Justicia (8.4.1976, Defrenne II, Rs. 43/75, 1976, 455, ap. 38/39).

48 Art. 9.3 S. 2 GG; art. 28.1 BV, veáse también R. J. Schweızer, en B. Ehrenzeller/B. Schindler/R. J. Schweizer/K. A. Vallender (n. ${ }^{\circ} 28$ ), art. 35 BV ap. 60 y ss., con ejemplos de la jurisprudencia.

$49 \S 1.6$ Datenschutzgesetz - DSG, BGBl. 1978/565; de acuerdo con BGBl. I 2012/51, la eficacia directa se encuentra en art. 1 \$ 1 Abs. 1 DSG 2000 (RV 2168 BlgNR 24. GP 6); pero más acertado sería invocar el apartado 2.

50 Por ejemplo, el parlamentario E. E. VESELSKY en la Comisión parlamentaria DSG, StenProtNR, 14. GP, 104. Reunión de 18.10.1978, 10228.

51 En especial la Directiva 95/46/EG del Consejo y del Parlamento Europeo de 24 de octubre de 1995 relativa a la protección de las personas físicas en el ámbito del tratamiento de los datos personales y a la libre circulación de datos, DOUE L 281/1995, 31. 
han surgido nuevas vinculaciones a los derechos fundamentales también entre particulares, y el fenómeno puede seguir creciendo $^{52}$.

\section{DEL MONOPOLIO DE LA FUERZA AL PODER DESCENTRALIZADO}

\section{Coacción}

Si se contemplan los ámbitos en que se han intensificado las obligaciones derivadas de los derechos fundamentales también para los particulares, aparece bajo una nueva luz la segunda premisa del relato tradicional, según la cual los derechos fundamentales son la respuesta al monopolio estatal de la fuerza ${ }^{53}$. La idea de fuerza remite a la coacción física, con la que el Estado amenaza y que puede ejercer a través de un aparato profesional ${ }^{54}$. La amenaza y el uso de la fuerza son desde el siglo XIX instrumentos centrales del poder del Estado, que prohíbe, ordena, sanciona, encierra, desplaza o deporta. Este tipo de poder se percibe y se siente incluso físicamente y de modo directo, no da rodeo alguno. Se manifiesta en la negación de la libertad ${ }^{55}$, y justo por eso necesita el contrapeso de ciertas garantías ${ }^{56}$.

\section{Dinero}

El poder no se ejerce solamente con la aplicación de la fuerza física; surge también en las relaciones de dependencia que genera el predominio económico. El Estado posee también este tipo de poder; por decirlo de algún modo, fue su instrumento de dominio durante la parte final del siglo xx: el Estado que presta

52 Todavía está sin decidir si la Carta acabará desarollando efecto directo. Según el Tribunal de Justicia, los particulares ya están directamente vinculados a las libertades fundamentales y a la prohibición de discriminación (PERner, Grundfreibeiten [n. ${ }^{\circ}$ 42], 146 y ss., 156 y ss.), por lo que no se ha de excluir que esto también ocurra con algunos derechos de la Carta; lo considera posible por ejemplo M. POTACs, «Systematik und Durchsetzung des (neuen) Grundrechtsschutzes», en C. Grabenwarter/W. Pöcherstorfer/C. Rosenmayr-Klemenz (dirs.), Die Grundrechte des Wirtschaftslebens nach dem Vertrag von Lissabon, 2012, 1 (10 y ss.); del mismo modo S. SCHOLZ, «Die Drittwirkung der gesellschaftspolitischen Diskriminierungsverbote der Europäischen Grundrechtecharta», en T. Horvath/R. Lebesmühlbacher/F. Lehne/M. Lütte/I. Murer (dirs.), Ungleichbeit im aktuellen Diskurs, 2013, 17 (31 y ss.).

53 Véase G. Birtsch, «Einleitung: Die Geschichte der Grund- und Freiheitsrechte als Gegenstand der Forschung» en el libro dirigido por él mismo Grund- und Freiheitsrechte im Wandel von Gesellschaft und Geschichte, 1981, 11 (18): «La historia de los derechos fundamentales es el verdadero reverso de la historia del poder»; también M. KRIELE, «Zur Geschichte der Grund- und Menschenrechte», FS Scupin, 1973, 187 (194 y ss.); K. STERn, Das Staatsrecht der Bundesrepublik Deutschland, Vol. III/1, 1988, § 59 I 5.

54 Véase WeBer, Wirtschaft und Gesellschaft (n. ${ }^{\circ}$ 3), 1042 y ss., y J. IsENSEE, «Das staatliche Gewaltmonopol als Grundlage und Grenze der Grundrechte», FS Sendler, 1991, 39 (46 y ss.).

55 B.-C. Han, Psychopolitik. Neoliberalismus und die neuen Machttechniken, 2014, 25 y ss.

56 Es representativo de esta idea G. JELLINEK, System der subjektiven öffentlichen Rechte, 2. ed. 1905, 103: «Toda libertad es simplemente libertad frente a la coacción ilegítima». 
servicios, el Estado benefactor, encargado de la «procura social» ${ }^{57}$, que distribuye, subvenciona, encarga tareas, cubre necesidades, busca empleo, construye viviendas, genera infraestructuras y eleva el bienestar general. En un principio no se imaginó que todas estas comodidades pudiesen poner en riesgo los derechos fundamentales $^{58}$. Tras algunas discusiones, se aceptó que el Estado está igualmente vinculado a los derechos fundamentales cuando no ejerce coacción, esto es, al actuar como un particular más ${ }^{59}$.

El dinero, a diferencia de la fuerza, no es monopolio del Estado; comparte esta fuente de poder con los particulares. En cualquier caso, como hemos visto, los derechos fundamentales obligan de manera específica a los poderes económicos privados: a través del deber de contratación que vincula a los monopolios ${ }^{60}$, mediante el principio de igualdad laboral ${ }^{61}$ o las prohibiciones de discriminación ${ }^{62}$, con exigencias que por tanto obligan también al Estado cuando actúa como particular.

Por otro lado, no se debe minusvalorar la existencia de multinacionales cuyos ingresos anuales son superiores al producto interior bruto de algunos Estados ${ }^{63}$. Estos actores ponen en juego su poder frente a otros particulares y frente a los propios Estados, con un éxito que crece a medida que éstos dependen del dinero ajeno ${ }^{64}$. Ahora bien, el acuerdo entre el dinero privado y el poder estatal es una amenaza seria a los derechos fundamentales, tal y como ilustra la presencia de Shell en Nigeria ${ }^{65}$.

\section{Información}

El poder no solo se ejerce a través de la fuerza y el dinero. Emerge igualmente en su forma más sutil, con la información, que el Estado también emplea como

57 F. Ewald, L'État providence, 1986 (en alemán: Der Vorsorgestaat, 1993).

58 H. F. ZaCHER, «Verwaltung durch Subvention», VVDStRL 25 (1967), 308, habla de los «velados favores estatales»; sobre las posibles amenazas a los derechos fundamentales ligadas a los mismos, 343 y ss., 363 y ss.; véase también F. OsSEnbüHL, VVDStRL 29 (1971), 171; W. MarTens y P. HÄBERLE, «Grundrechte im Leistungsstaat», VVDStRL 30 (1971), 7 y ss. y 43 (69 y ss.).

59 Véase para Alemania W. RüFNER, HStR IX, 3. ed. 2011, § 197 ap. 68 ff., en especial ap. 77; para Austria G. KUCSKO-STADlmayer, «Strukturen» (n. $\left.{ }^{\circ} 30\right), \S 3$ ap. 49 y ss.; para Suiza KIENER/KäLIN, Grundrechte $\left(\mathrm{n} .^{\circ} 22\right), 46$ y ss.

60 Véase la n. 43.

61 Véase las nn. 44 y 46.

62 Veánse las nn. 46, 47 y 52.

63 Por ejemplo, Royal Dutch Shell, en el año 2012, tuvo ingresos superiores al producto interior bruto de 171 Estados; está entre las 26 mayores empresas del mundo, al respecto y con información sobre otras empresas T. S. Keys/T. W. Malnight/C. K. SToklund, Corporate Clout 2013: Time for Responsible Capitalism, 2013, www.globaltrends.com/reports/?doc_id=500539\&task=view_details (31.10.2014).

64 Véase GüNTHER en Deitelhoff/Steffek (n. ${ }^{\circ}$ 8), 274 y ss. Es frecuentemente cierto que «los particulares, a diferencia del Estado, se encuentran en relación mutua de concurrencia y dependencia», como señala Müller-Franken, «Bindung» (n. $\left.{ }^{\circ} 28\right), 231$, pero no siempre: también los Estados pueden estar en relación de dependencia con algunos particulares.

65 Con más detalle IV.3. 
medio de dirección de modo creciente; en cierta medida es el instrumento de dominio estatal a principios del siglo XXI: el Estado social, cuantiosamente endeudado, ni prohíbe ni sanciona, cada vez distribuye menos; a cambio ofrece, sin embargo, más comunicación: el Estado aclara, distingue, aconseja, recomienda, avisa; son tareas para las que nunca recibe la suficiente información, así que reúne conocimientos, encuesta y registra a sus ciudadanos, crea bases de datos, los integra con su propia cooperación en todo esto y despliega su poder de dirección «dentro de la cabeza de las personas» ${ }^{66}$, alcanzando efectos que no lograría con prohibiciones y sanciones ${ }^{67}$.

Este poder es casi imperceptible y desde luego no se percibe físicamente de manera directa; en general es indireto y por eso cuesta controlarlo ${ }^{68}$. Sin embargo, poco a poco se le va embridando mediante los derechos fundamentales y, por ejemplo, los tribunales han establecido claramente que las advertencias estatales (respecto de alimentos ${ }^{69}$, sectas ${ }^{70}$ o servicios financieros ${ }^{71}$ ) también han de controlarse conforme a los derechos fundamentales ${ }^{72}$.

Pero la pretensión de monopolizar la información es simplemente ilusoria. El Estado debe compartir con los particulares esta fuente de poder, incluso se la cede. Se explica así que el derecho europeo de la protección de datos, aunque no siempre lo logre ${ }^{73}$, busque disciplinar a los particulares, a los que impone obligaciones similares al Estado.

Los particulares usan de manera intensiva el poder de la información, en especial esos gigantes de internet que «permanentemente nos requieren para que les comuniquemos [...] nuestras opiniones, necesidades, deseos, preferencias y para que les contemos nuestra vida» ${ }^{74}$. En la realidad actual, nos damos a conocer

66 Di FABio, Selbstregulierung (n. ${ }^{\circ}$ ), 239.

67 Respecto al «Derecho administrativo como orden de la información y la comunicación», véanse las contribuciones en W. Hoffmann-Riem/E. Schmidt-Assmann/A. Vosskuhle (dirs.), Grundlagen des Verwaltungsrechts, Vol. II Informationsordnung, Verwaltungsverfahren, Handlungsformen, 2. ed. 2012, 1 y ss.

68 Véase Di Fabio, «Selbstregulierung» (n. ${ }^{\circ}$ 3), 254 y ss., desde otra perspectiva Han, Psychopolitik (n. ${ }^{\circ}$ 55), 25: «Cuanto mayor es el poder, más silenciosamente actúa» (subrayado en el original), 27: «El poder inteligente y amigable no opera de manera frontal contra la voluntad del sujeto sometido, sino que dirige su voluntad en provecho propio [...] En vez de situarse frente a los sujetos, los acompaña.»

69 BVerfGE 105, 252.

70 BVerfGE 105, 279.

71 VfSlg. 18.747/2009.

72 Encontramos un desarrollo doctrinal en M. IBLER, «Grundrechtseingriff und Gesetzesvorbehalt bei Warnungen durch Bundesorgane», FS Maurer, 2001, 145.

73 Respecto a los déficits y la necesidad de una reforma, por ejemplo A. Rossnagel, «Modernisierung des Datenschutzrechts für eine Welt allgegenwärtiger Datenverarbeitung», MMR 2005, 71; W. BerKa, Das Grundrecht auf Datenschutz im Spannungsfeld zwischen Freibeit und Sicherbeit, Gutachten für den 18. Österreichischen Juristentag, Bd. I/1, 2012, 40 y ss.; T. WEICHERT, «Die Kontrolle durch die Datenschutzbeauftragen - Handlungsgrenzen und Handlungsmöglichkeiten, insbesondere im Lichte des neuen EU-Rechts», en H. Hill/M. Martini/E. Wagner (dirs.), Facebook, Google E Co, 2013, 127 y ss.; D. ENNÖCKL, Der Schutz der Privatsphäre in der elektronischen Datenverarbeitung, 2014, 579 y ss.

74 Han, Psychopolitik (n. ${ }^{\circ}$ 55), 27. 
permanentemente en internet, dónde estamos, qué hacemos, qué pensamos hacer, y lo documentamos todo con las correspondientes fotos. Medimos y compartimos incluso los datos referidos a nuestro cuerpo: gasto de calorías, actividad eléctrica del cerebro, fases de sueño y vigilia ${ }^{75}$. Esta permanente auscultación y control, a diferencia de lo que habitualmente se afirma, poco tiene que ver con el Estado policial de Orwell. En el mundo digital «no se tortura: se lanzan tweets o posts»; no se arrancan confesiones por la fuerza, el desnudo es voluntario ${ }^{76}$. Por esto es tan inteligente el poder de la información: no niega la libertad, se aprovecha de ella ${ }^{77}$. Pese a que se siente plenamente libre, cada uno hace de sí mismo su propio controlador $^{78}$. Por tal razón apenas hubo inicialmente resistencias frente a este poder, que no necesita de la coacción; en esta ausencia de coacción radica su fuerza, pues confiamos a nuestros miles de «amigos» en facebook lo que nunca le diríamos voluntariamente al Estado. Así la capacidad del prestador del servicio de internet para acercarse a la intimidad de las personas, de masas humanas, le hace, más allá de su dinero, especialmente interesante para un Estado hambriento de datos. Esta circunstancia mina la disposición del Estado para proteger a la ciudadanía frente a estos intermediarios ${ }^{79}$.

\section{DEL TERRITORIO A LA AUSENCIA DE FRONTERAS}

\section{El dominio se ejerce en casa}

La tercera premisa del drama de los derechos fundamentales está ligada a los problemas adicionales que origina el hecho de que los nuevos intermediarios operen más allá de las fronteras, o incluso, como refleja internet, en un mundo sin fronteras. La imagen maestra de los derechos fundamentales simplemente no conoce estos fenómenos. Bajo la palabra clave «frontera» se informaba sobre las

75 El llamado self-tracking (monitorización autónoma), véase por ejemplo, J. WiLLMroth, «Regieraum des Lebens», Süddeutsche.de, 23.7.2014.

76 Han, Psychopolitik (n. $\left.{ }^{\circ} 55\right), 18$ y ss., 54 y ss.

77 Respecto al modo de funcionamiento de estos «poderes inteligentes», véase HaN, Psychopolitik (n. $\left.{ }^{\circ} 55\right), 25$ y ss.

78 Han, Psychopolitik (n. $\left.{ }^{\circ} 55\right), 19,23$.

79 En este sentido se critica por ejemplo que la demanda de la Comisión Europea contra Google en defensa de la competencia avanza demasiado despacio (véase por ejemplo M. DöPfNER, «Warum wir Google fürchten», faz.net, 16.4.2014; C. ARTHUR, «European commission reopens Google antitrust investigation», theguardian.com, 8.9.2014; «EU-Kommission vs. Google: Druck auf den letzten Drücker», SPIEGEL ONLI$\mathrm{NE}, 23.9 .2014$ ) y que la reforma del régimen de protección de datos va en Europa con excesiva lentitud (por ejemplo, P. BEUTHM «Reform des EU-Datenschutzes ist erst einmal abgesagt», ZEIT ONLINE, 23.1. 2014; «Ringen um EU-Datenschutz geht in entscheidende Runde», derstandard.at, 29.7.2014); de ello se ha hecho responsable al lobby de los grandes prestadores de servicios de internet (por ejemplo, K. O'BrIEN, «Silicon Valley Companies Lobbying Against Europe’s Privacy Proposals», nytimes.com, 25.1.2013; U. EBBINGHAUS/S. SChulz/T. Thiel, «Machtprobe mit Silicon Valley», faz.net, 11.3.2014). 
dificultades de los Estados para extender su dominio hasta el último rincón del territorio $^{80}$. Pero su domino también terminaba en la frontera del Estado. La premisa de la imagen maestra parte de un Estado que domina su casa, y también es ahí donde vinculan los derechos fundamentales ${ }^{81}$.

Esta premisa está sometida hoy a una doble presión. De un lado, fruto de la cooperación internacional de las instituciones, los Estados actúan cada vez más en territorios de dominio ajeno ${ }^{82}$. En ocasiones incluso trasladan conscientemente actos de soberanía a espacios cuyo dominio es inseguro, incierto o nulo, como es el caso, entre otros, de Guantánamo ${ }^{83}$. Actualmente, además, con la ayuda de técnicas avanzadas, los Estados actuarían en el territorio de otros Estados sin estar físicamente presentes, por ejemplo controlando la comunicación mundial desde el espacio o a través de cables submarinos ${ }^{84}$. La política exterior del Estado se transforma en política interior del mundo, y aquí también se esfuman las certi-

80 Esta narración se concentra claramente en el Estado-nación; ya no se adapta al Imperio, «cuyas fronteras son menos claras y se encuentran allí donde están «los salvajes» o «los bárbaros», o bien otro Imperio», J. Osterhammel, Die Verwandlung der Welt. Eine Geschichte des 19. Jabrhunderts, 2009, 607.

81 Esta compresión se hace muy clara en el art. 2 PIDCP, de acuerdo con el cual todo Estado miembro está obligado «a garantizar los derechos del Pacto en favor de las personas que se encuentren en su territorio y bajo su jurisdicción».

82 Respecto a la creciente cooperación entre autoridades en la Unión Europea, por ejemplo W. WeIss, Der europäische Verwaltungsverbund, 2010; M. Holoubek/M. LANG (dirs.), Verfabren der Zusammenarbeit von Verwaltungsbehörden in Europa, 2012; en especial sobre la actuación de los órganos en territorios extranjeros véase por ejemplo L. HARINGS, «Grenzüberschreitende Zusammenarbeit der Polizei- und Zollverwaltungen», en E. Schmidt-Assmann/B. Schöndorf-Haubold (dirs.), Der Europäische Verwaltungsverbund, 2005, 127 y ss.

83 Véase por ejemplo la persecución transfronteriza de los sospechosos de terrorismo por parte de la CIA en el marco del «extraordinary rendition programme», en el que han colaborado también Estados europeos (D. Priest, «CIA Holds Terror Suspects in Secret Prisons», The Washington Post, 2.11.2005). Recientemente esto ha hecho que Polonia fuese condenada por el TEDH por aceptar que dos detenidos por los Estados Unidos fueran torturados en territorio polaco por parte de la CIA, EGMR 24.7.2014, Al Nashiri v. Polen, Appl. 28761/11 y Husayn (Abu Zubaydah) v. Polen, Appl. 7511/13. Hay otras demandas contra Rumanía y Lituania, todavía pendientes (Al Nashiri v. Rumänien, Appl. 33234/12) (Abu Zubaydah v. Litauen, Appl. 46454/11).

84 Respecto a esta vigilancia por parte de los servicios secretos, el llamado «Five Eyes», véase el apartado IV.4. En el marco de esa vigilancia, se dice que los trabajadores de la NSA incluso paralizaron por descuido el servicio de internet en Siria (J. BAMFORD, «The most wanted man in the world», Wired 9/2014, 22.9.2014, www.wired.com/2014/08/edward-snowden/, 31.10.2014). El servicio secreto británico, entre otras cosas, habría manipulado sondeos a través de internet (G. GreENWALD, «Hacking Online Polls and Other Ways British Spies Seek to Control the Internet», The Intercept, 14.7.2014, https://firstlook.org/theintercept/ 2014/07/14/manipulating-online-polls-ways-british-spies-seek-control-Internet/, 31.10.2014). Los mismos objetivos se alcanzan cuando un Estado, como al parecer habría hecho Rusia, encarga intervenciones masivas para influir sobre la opinión en los foros de internet de otros países, J. HaNs, «Putins Trolle», Sueddeutsche.de, 13.6.2014. Los sistemas de navegación por satélite (GPS para los Estados Unidos, Glonass para Rusia, pero también los usan otros Estados) también permiten ejercer influencias extraterritoriales. Son gestionados por fuerzas militares que, según afirman los medios, pueden falsear o interrumpir ocasionalmente su funcionamiento. Habría ocurrido en la guerra de Kosovo, motivando que la Unión desarrollase su propio sistema de satélites, el llamado Galileo, A. Gras, «Galileo mit zwei Gesichtern», die tageszeitung, 10.1.2010; «Falsche Umlaufbahn: EU-Kommission fordert Aufklärung nach «Galileo»-Debakel», SPIEGEL ONLINE, 25.8.2014. 
dumbres que ofrecían los pares conceptuales en relación dialéctica, como interior/ exterior.

Por lo demás, la movilidad de los actores privados ha crecido aún a mayor velocidad. Si disponen de suficiente dinero o poder de información, se comportan igual que los Estados: fundan sucursales en zonas libres de derechos fundamentales, llevándolas a Estados con escaso nivel de protección o desarrollo de los derechos fundamentales, y cooperan con sus gobiernos ${ }^{85}$. En ocasiones incluso escapan hacia territorios sin control y por ejemplo fletan barcos de trabajo en alta mar con condiciones similares a la esclavitud ${ }^{86}$. Además, los prestadores del servicio de internet pueden incidir de modo intensivo sobre la vida de los ciudadanos de un Estado sin estar físicamente presentes en su territorio ${ }^{87}$.

Todo esto supone un reto para nuestro concepto de derechos fundamentales, que no se ha construido pensando en Estados que se van de viaje y, por tanto, no tiene respuesta clara sobre si la vinculación a los derechos fundamentales termina en la frontera del Estado o si le acompaña, y, de ser así, hasta dónde y por cuánto tiempo. ¿Debe el Estado incorporar al equipaje de los actores privados que intervienen en el extranjero estándares de protección de los derechos fundamentales? ¿Deben los Estados proteger a sus ciudadanos frente a los actores que actúan desde el extranjero?

\section{Actores privados que actúan desde el extranjero}

Miles de personas se han planteado esta última pregunta en los últimos años, en especial el español Mario Costeja González ${ }^{88}$. Como lamentablemente se sabe hoy en todo el mundo, hace dieciséis años se vio forzado a sacar una propiedad a subasta. De acuerdo con las leyes, el procedimiento de ejecución se hizo entonces público en un periódico. Años después, el servidor Google dirigía a este anuncio a todo el que buscara información sobre la citada persona. Esta se quejó ante la

85 En detalle IV.3.

86 Por ejemplo, las condiciones en las que se pescan los camarones en Thailandia, K. Hodal/C. KELLY/F. LAWRENCE, «Revealed: Asian slave labour producing prawns for supermarkets in US, UK», theguardian.com, 10.6.2014. El Seasteading Institute investiga cómo se podrían construir ciudades flotantes sobre el mar; Google, entre otros, está interesado en esas ciudades, para probar a vivir al margen de las reglas de un Estado, G. Hamann/K. Pham/H. Wefing, «Die Vereinigten Staaten von Google», Die Zeit, Dossier, 7.8.2014.

87 Se piensa especialmente en prestadores del servicio de internet como Google o Facebook, en detalle por ejemplo Hill/Martini/Wagner, Facebook (n. ${ }^{\circ}$ 73). Sobre los efectos de globalización de internet y los problemas de su regulación G.-P. CALliess, «Globale Kommunikation — staatenloses Recht. Zur (Selbst-) Regulierung des Internet durch prozedurales Recht am Beispiel des Verbraucherschutzes im elektronischen Geschäftsverkehr», ARSP-Beiheft 79, 2001, 61; U. SCHLIESKy/C. HofFMANN/A. D. LuCH/S. E. SCHulz/K. C. Borchers, Schutzpflichten und Drittwirkung im Internet, 2014, en especial 119 y ss.

88 Respecto al supuesto de hecho de este caso, Tribunal de Justicia 13.5.2014 (Gran Sala), Google v. Mario Costeja González, Rs. C-131/12, ap. 14 y ss., 43. 
Agencia Española de Protección de Datos, solicitando que Google eliminase el vínculo. Dirigió su petición frente a Google Inc., titular del buscador en los Estados Unidos ${ }^{89}$, y frente a Google Spain, que desarrolla la actividad comercial de Google en España.

Esta historia, breve en sus hechos, es de gran complejidad desde la perspectiva de los derechos fundamentales, pues aparentemente los del señor Costeja tenían tres enemigos difusos. En primer lugar, el usuario de internet que pretende formarse una imagen de él (a la postre, en potencia, toda la comunidad de internet). A continuación, el periódico que informó sobre el procedimiento de ejecución, y con él todas las personas que hicieran lo mismo. La información, quizá muy extendida en la red, sólo se localiza mediante el buscador de la empresa Google, cuya sede sin embargo está situada en los Estados Unidos, por lo que no se siente sometida al derecho europeo de protección de datos, y además discute el mismo hecho de estar procesando datos, alegando que el buscador simplemente hace suya información ya publicada y la ordena según los intereses expresados por la comunidad en red, sin saber si se trata de datos personales y sin poder controlarlos $^{90}$. Dicho de otro modo: el ex deudor Mario Costeja González es un buen ejemplo de la inabarcabilidad multipolar que hoy distingue los conflictos de derechos fundamentales y que provoca que el ciudadano a menudo se resigne en la defensa de sus derechos.

Es llamativo cómo el Tribunal de Justicia —al que planteó cuestión prejudicial la Audiencia Nacional española - reduce la complejidad del caso, situando a Costeja en el centro de sus reflexiones y analizando desde ahí el resto de posiciones en juego.

Así, en primer lugar, considera el Tribunal de Justicia que Google no puede ocultarse detrás del periódico o de la comunidad que usa internet; él es la bisagra que une a los dos. El hecho de que Google localice datos (también) personales, los ordene y los disponga en la lista de búsquedas supone un procesamiento de datos que materialmente se encuadra bajo la protección de la Directiva europea de protección de datos y que, por tanto, hace también responsable a Google ${ }^{91}$.

En segundo lugar, que este tratamiento de datos se realice en los Estados Unidos no libera a Google de sus obligaciones, dado que su actividad está ligada de modo inseparable con la publicidad que gestiona la sucursal española, lo cual hace aplicable la directiva desde el punto de vista territorial ${ }^{92}$. El Tribunal de Justicia trata a Google, pues, como a un Estado: la organización interna del trabajo carece de consecuencias externas; y, del mismo modo que los Estados no se

89 Los datos se conservan en servidores; dónde se encuentran estos servidores es algo que se oculta para evitar la competencia, Tribunal de Justicia, 13.5.2014, Google v. Mario Costeja González, Rs. C-131/12, ap. 43.

90 Tribunal de Justicia, 13.5.2014, Google v. Mario Costeja González, Rs. C-131/12, ap. 22.

91 Tribunal de Justicia, 13.5.2014, Google v. Mario Costeja González, Rs. C-131/12, ap. 25 y ss.

92 Tribunal de Justicia, 13.5.2014, Google v. Mario Costeja González, Rs. C-131/12, ap. 48 y ss. 
liberan de su vinculación a los derechos fundamentales cuando actúan a través de particulares, tampoco escapa Google de sus vínculos de derecho europeo cuando alega que el tratamiento de datos se ha realizado en los Estados Unidos.

En tercer lugar, el procesamiento realizado por Google, en la medida que facilita a cualquiera un perfil detallado sobre el señor Costeja, afecta de manera significativa a su derecho a la vida privada y a su derecho a la protección de datos personales ${ }^{93}$. Los «intereses económicos» ${ }^{94}$ de Google no justifican de ninguna manera esta injerencia ${ }^{95}$. El interés informativo del usuario de internet ${ }^{96}$ justifica la intervención sobre los derechos solo en determinados supuestos, que dependerían del tipo de información, su sensibilidad para la vida privada y el papel que ocupa el afectado en la vida pública ${ }^{97}$. De este modo, la carga argumentativa está claramente repartida: en caso de duda (como ocurre en el supuesto concreto ${ }^{98}$ ) tienen preferencia los derechos de Costeja.

En cuarto lugar, de acuerdo con estos derechos fundamentales, Costeja puede exigir a Google que haga desaparecer de los resultados de cualquier búsqueda la información que le afecta, incluso cuando esta información es materialmente correcta y su procesamiento estuvo justificado en un principio, pues el paso del tiempo ha difuminado la trascendencia del dato ${ }^{99}$. En el futuro Google deberá decidir sobre una solicitud de cancelación a la luz de una cuidadosa ponderación de intereses conforme a los mencionados criterios ${ }^{100}$. Para realizar estas complejas

93 Tribunal de Justicia, 13.5.2014, Google v. Mario Costeja González, Rs. C-131/12, ap. 36 y ss. y 80 .

94 No su libertad empresarial (art. 16 de la Carta).

95 Tribunal de Justicia, 13.5.2014, Google v. Mario Costeja González, Rs. C-131/12, ap. 81, 97 y 99.

96 Y no su libertad de información (art. 11 de la Carta).

97 Tribunal de Justicia, 13.5.2014, Google v. Mario Costeja González, Rs. C-131/12, ap. 81, 97 y 99.

98 Tribunal de Justicia, 13.5.2014, Google v. Mario Costeja González, Rs. C-131/12, ap. 98.

99 Tribunal de Justicia, 13.5.2014, Google v. Mario Costeja González, Rs. C-131/12, ap. 93 y ss. En la bibliografía este fenómeno se calificó como «derecho al olvido» o «derecho a ser olvidado», véase, por ejemplo M. Arning/F. Moos/J. SchefZIG; «Vergiss(,) Europa!», CR 2014, 447; J. CASPAR, «Besprechung des EuGH-Urteils vom 13. Mai 2014 in dem Verfahren C-131/12», Ping 2014, 133 (135); J. KüHLING, «NJW-Editorial», NJW 2014; C. PILTZ, «Nach dem Google-Urteil des EuGH: Analyse und Folgen für das Datenschutzrecht», KER 2014, 566 (569). Pero el Tribunal de Justicia no utiliza esta fórmula. En cualquier caso, las condiciones que fija para la cancelación de datos muestran que no postula un derecho absoluto al olvido; simplemente eleva las posibilidades de que cierta información sea olvidada, véase JANDT, «EuGH stärkt den Schutz der Persönlichkeitsrechte gegenüber Suchmaschinen», MMR-Aktuell 2014, 358242. Por lo demás, el proyecto de reglamento general relativo a la protección de datos prevé en su artículo 17 un «derecho a ser olvidado», que, aunque la formulación lo sugiere, no es un derecho a un olvido pleno; se limita a aclarar las posibilidades ya existentes de solicitar el borrado de datos y a añade al deber de suprimirlos determinadas obligaciones de información, véase G. HoRNung/K. HofmanN, «Ein «Recht auf Vergessenwerden»?», JZ 2013, 163 (165 y ss.); M. LANG, «Google Search und das «Recht auf Vergessenwerden»», KER 2014, 449 (451).

100 Tribunal de Justicia, 13.5.2014, Google v. Mario Costeja González, Rs. C-131/12, ap. 77, 96 y ss. Arning/Moos/Schefzig (n. $\left.{ }^{\circ} 99\right)$, 455, consideran que el Tribunal de Justicia ha convertido a Google en una «autoridad privada encargada de la censura previa»; pero esto no es correcto, sino que más bien, siguiendo el reflejo que con razón critica O. Diggelmann, «Grundrechtsschutz durch Privatheit», VVDStRL 70 (2011), 50 (76 y ss.), supone desacreditar como censura el freno a la indiscreción: no hay en realidad censura previa porque, por definición, toda cancelación de datos se produce a posteriori. Por otro lado, el sentido de la 
ponderaciones, Google ha establecido un consejo que fija una serie de directrices internas ${ }^{101}$. Si no elimina la información derivada de una búsqueda, el solicitante debe tener acceso a la tutela de la autoridad nacional de protección de datos ${ }^{102}$.

En quinto lugar, Costeja no necesita dirigir su reclamación de cancelación también contra quien generó la información originariamente, esto es, el periódico y una multitud de personas potencialmente infinita ${ }^{103}$, sino que directamente puede solicitarlo a una sola, cuyo motor de búsqueda constituye la llave de la distribución de información ${ }^{104}$.

Finalmente, el Tribunal de Justicia ha reducido un conflicto de apariencia multipolar a una relación bipolar de derechos fundamentales, en la cual el ciudadano puede imponer la eficacia de sus derechos fundamentales. ¿Qué enseñanzas generales pueden deducirse de este caso?

$\mathrm{Al}$ igual que los Estados, los particulares intentan liberarse de las vinculaciones jurídicas trasladando sus actividades sensibles a otros ordenamientos. Vincular estas actividades a los derechos fundamentales es difícil, pero posible si el Estado extiende correlativamente su jurisdicción.

Quienes pueden realizar tales actuaciones habitualmente tienen gran influencia al disponer de mucho dinero o poder de información. Esto puede frenar

cancelación, a diferencia de la censura previa, es proteger derechos personales. Finalmente, debe recordarse que, cuando se trata de informaciones delicadas, los medios siempre deben ponderar, antes de publicarlas, si los derechos de la personalidad se imponen sobre los intereses generales de la información, y a nadie se le ocurre calificar esto como «censura privada».

101 Este consejo lo integran expertos del ámbito de la ciencia, los medios, la protección de datos, la sociedad civil y la tecnología, entre ellos también la antigua ministra de Justicia de Alemania; el consejo realizó audiencias públicas de expertos en siete ciudades europeas y a partir de ahí debe formular orientaciones sobre el modo de ponderar, en caso de solicitud de cancelación, los intereses privados del solicitante frente a los públicos, para más detalles D. Drummond, «We need to talk about the right to be forgotten», theguardian.com, 10.7.2014; «Google beruft Leutheusser-Schnarrenberger in «Lösch-Beirat»», faz.net, 10.7.2014; la página web se encuentra en www.google.com/advisorycouncil/ (31.10.2014), donde se pueden consultar las audiencias celebradas.

102 Tribunal de Justicia 13.5.2014, Google v. Mario Costeja González, Rs. C-131/12, ap. 77 y ss. Esta decisión no contiene ninguna referencia expresa a la cuestión de si la cancelación debe tener efectos globales o, como pretende Google, solo dentro de la Unión. Si el borrado solo se produjese en las páginas europeas, la información permanecería en otros buscadores de Google, como www.google.com, y no habría problema para encontrarla desde Europa. Ese derecho a la cancelación quedaría en simple proclama, por lo que que un tribunal canadiense ha rechazado la pretensión de Google de los borrados con alcance territorial limitado, Equustek Solutions Inc. v. Jack, 2014 BCSC 1063, ap. 148. También es escéptico respecto a la prácticas de borrado de Google Caspar, «Besprechung» (n. ${ }^{\circ}$ 99), 137.

103 Tribunal de Justicia, 13.5.2014, Google v. Mario Costeja González, Rs. C-131/12, ap. 82 y ss., una interdependencia de ese tipo dejaría sin protección al afectado, porque la información a cancelar puede haberse hecho pública en muchas páginas, porque los responsables de ello no están necesariamente sometidos al Derecho de la Unión, o porque en virtud de los privilegios que corresponden a los medios de comunicación o de otros intereses justificados pueden no estar obligados a cancelar. El afectado, tal y como ha expresado un tribunal canadiense, estaría sometido al interminable juego del Whac-a-mole, donde siempre aparece un nuevo topo por alguno de los infinitos agujeros, y debería someterlo con la ayuda judicial, véase Equustek Solutions Inc. v. Jack, 2014 BCSC 1063, ap. 72.

104 Sobre esta función de llave que corresponde al motor de búsqueda, Tribunal de Justicia, 13.5.2014, Google v. Mario Costeja González, Rs. C-131/12, ap. 36, 87. 
la disponibilidad del legislador a ordenar la debida protección, incluso cuando se trata de los derechos de la mayoría ${ }^{105}$. En esas situaciones aparecen de vez en cuando tribunales con decisiones espectaculares que abren brecha en favor de los ciudadanos, cubriendo la falta de protección legislativa con la aplicación directa de los derechos fundamentales ${ }^{106}$. A diferencia de lo que es habitual en democracia, los derechos fundamentales no protegen entonces a una minoría frente a la mayoría, sino que, al igual que en el siglo XIX, protegen más bien a la mayoría frente al dominio de un intermediario.

Esas sentencias pueden impulsar un proceso de juridificación, que en una situación ideal conduciría a la mejora de las normas de protección desarrolladas por la judicatura ${ }^{107}$. Si la regulación normativa es complicada porque requiere la cooperación entre Estados, entonces los particulares pueden ocupar el espacio del legislador y concretar las reglas judiciales, como ha ocurrido en el caso Google incluso con efecto transfronterizo ${ }^{108}$.

Esta sentencia además nos ha mostrado que las perturbaciones difusas y evanescentes de los derechos fundamentales, como la que provoca la comunidad de internet, son controlables cuando la injerencia es imputada teniendo en cuenta la necesidad de proteger los derechos fundamentales y se ofrece así al afectado un sujeto contreto al que demandar, en este caso Google, que es quien convierte en efectiva la comunidad de internet. Es en esta línea por donde está creciendo la actividad de los tribunales nacionales, que por ejemplo imponen a los gestores de los foros una protección suficiente frente a mensajes de usuarios anónimos que insultan o agreden verbalmente ${ }^{109}$.

105 Véase la nota 79.

106 Es discutible que la decisión del Tribunal de Justicia en el asunto Google v. Mario Costeja González respete la Directiva de protección de datos en todos los puntos; en especial, se pone en duda que la Directiva sea aplicable territorialmente, véase, por ejemplo, ARning/Moos/SCHEFZIG, «Vergiss» (n. ${ }^{\circ}$ 99), 449 y ss.; Piltz, «Google-Urteil» (n. ${ }^{\circ}$ 99), 567; también se constata una superación de los términos literales de la Directiva, LANG, «Google Search» (n. $\left.{ }^{\circ} 99\right)$, 450, que podría considerarla justificada por consideraciones relativas a los derechos fundamentales. Ciertamente, llama la atención que el Tribunal de Justicia se apoye (al menos también) en los derechos fundamentales para abordar todas las cuestiones relevantes, por ejemplo en ap. 38, donde la responsabilidad del motor de búsqueda se considera necesaria para lograr una efectiva protección de la vida privada; ap. 58, donde no se considera «aceptable» sustraer de las garantías ofrecidas por la Directiva el tratamiento de datos realizado por Google en Estados Unidos, porque esto conllevaría una limitación en la protección de los derechos fundamentales; ap. 68 y s., donde se establece que los artículos 6, 7, 12, 14 y 28 de la Directiva son un desarrollo de los artículos 7 y 8 de la Carta y, por tanto, deben leerse a la luz de estos derechos fundamentales; ap. 81, 97, 99, donde da preponderancia a los derechos fundamentales recogidos en los artículos 7 y 8 frente a los intereses del motor de búsqueda o de los usuarios de internet; o ap. 84 , donde se establece que los derechos del afectado no serían protegidos de modo efectivo y completo si la cancelación realizada en el motor de búsqueda dependiese de la cancelación previa o paralela en la página correspondiente.

107 En Alemania ya se han formulado reflexiones en este sentido a partir del caso Google, véase por ejemplo «Recht auf Vergessen braucht ein Gesetz», Handelsblatt.com, 25.5.2014.

108 Véanse en la nota 101 las referencias a las directrices del Consejo.

109 La judicatura alemana considera que los gestores de los portales tienen que vigilar más los comentarios emitidos en ellos cuanto más sea de temer que estos comentarios vulneren los derechos de la personali- 


\section{Los actores privados en el extranjero}

Bastante difícil es ya someter a la Directiva europea el procesamiento de datos realizado en los Estados Unidos, aunque provoque perjuicios en Europa. Pero todavía más difícil resulta proceder contra grupos multinacionales de gran poder económico que establecen sucursales en Estados con bajos estándares de regulación y control, cooperan con sus gobiernos y causan vulneraciones de los derechos fundamentales que sólo tienen lugar en tales Estados, por ejemplo el trabajo forzoso, el trabajo infantil, los desplazamientos forzosos de población, la represión violenta de protestas o incluso la participación en torturas ${ }^{110}$.

La población afectada normalmente no espera protección alguna en su Estado. El Estado de origen de la multinacional bien podría compensar este déficit obligándola a cumplir ciertos estándares también en el extranjero ${ }^{111}$. Sin embargo, por lo general se niega que los derechos humanos se lo impongan, que su deber de protección tenga un alcance extraterritorial ${ }^{112}$. Y evidentemente es difí-

dad y cuanto más graves puedan ser dichas vulneraciones; en su caso será obligado moderar los foros o controlar los comentarios antes de publicarlos, HAUG, «Die Haftung von Internetportalen für verletzende Nutzerkommentare», AfP 2014, 27 (29); para Austria vale de ejemplo la decisión del OGH 21.12.2006, 6Ob 178/04a, según la cual el gestor de un libro de visitas-online debe cancelar las entradas que lesionan evidentemente los derechos de terceros; el gestor tiene una especial obligación de comprobación cuando al menos ha sido informado de una vulneración y le consta así la posibilidad de nuevas vulneraciones. En England and Wales Court of Appeal (Civil Division), 14.2.2013, Tamiz v. Google Inc, se hace responsable a Google del contenido de un blog alojado en su servidor si no ha reaccionado con celeridad ante las reclamaciones frente a comentarios calumniosos; véase también la sentencia del TEDH 10.10.2013, Delfi AS v. Estland, recurso 64569/09, donde se considera conforme al Convenio que un portal de internet deba responder de los comentarios (en su mayoría anónimos o con pseudónimo) realizados por los usuarios sobre un artículo; la sentencia que fue asumida por la Gran Cámara mediante decisión de 17.2.2014.

110 Las empresas multinacionales pueden participar de muchos modos en tal vulneración de los derechos humanos: en parte financian vulneraciones de los derechos humanos realizadas por el Estado en el que se instalan, en parte se benefician de esas vulneraciones (por ejemplo de las expulsiones de población fuera de zonas con gran riqueza en materias primas); pueden también cometer por sí mismas vulneraciones (por ejemplo con trabajadores forzosos o trabajadores infantiles), véase A. PETERs, «Sind transnationale Unternehmen verpflichtet, (internationale) Menschenrechte zu respektieren und zu fördern?», en P. G. Kirchschläger/T. Kirchschläger/A. Belliger/D. J. Krieger (dir.), Menschenrechte und Wirtschaft, 2005, 127; GüNTHER, en Deitelhoff/Steffek (n. ${ }^{\circ}$ 8), 268 y ss., así como los estudios de casos en G. SKINNER/R. McCorquOdale/O. De Schutter/A. Lambe, The Third Pillar: Access to Judicial Remedies for Human Rights Violations by Transnational Business, 2013; J. ZERK, Corporate liability for gross human rights abuses, 2013.

111 Principio activo de personalidad véase W. MENG, Extraterritoriale Jurisdiktion im öffentlichen Wirtschaftsrecht, 1994, 56, 507 y ss. No choca con la soberanía del Estado anfitrión cuando este se ha obligado internacionalmente a respetar los estándares, J. BERNSTORFF, «Extraterritoriale menschenrechtliche Staatenpflichten und Corporate Social Responsibility», AVR 2011, 34 (58).

112 BernStORFF, «Staatenpflichten» (n. $\left.{ }^{\circ} 111\right), 55$ y ss; T. KoEnEN, Wirtschaft und Menschenrechte, 2012, en especial 206 y ss. Algunas Declaraciones de la Comisión del Pacto Social de Naciones Unidas remiten, tomadas de manera aislada, a obligaciones extraterritoriales, como por ejemplo la exigencia de que «States parties should also take steps to prevent human rights contraventions abroad by corporations which have their main offices under their jurisdiction, without infringing the sovereignty or diminishing the obligations of host States under the Covenant» (Social and Cultural Rights, Statement on the Obligations of States Parties Regarding the Corporate Sector and Economic, Social and Cultural Rights, 5, UN-Dok E/C.12/2011/1 v. 12.7.2011, ap. 5; se 
cil para los Estados proporcionar esa protección: al fin y al cabo debilita la competitividad de «sus» empresas imponiéndoles obligaciones, y lo hace para defender no a sus ciudadanos, sino a una población extranjera, que no votará en las siguientes elecciones ${ }^{113}$ : resulta poco seductor.

Por eso la protección de los derechos humanos en este campo solo funciona de manera indirecta ${ }^{114}$. Una vez más, el primer movimiento lo realizaron los tribunales, apoyándose en el Alien Tort Statute, una ley estadounidense de 1789 que reconoce la competencia de los jueces federales en las demandas de responsabilidad patrimonial presentadas por extranjeros que alegan la vulneración del derecho internacional ${ }^{115}$. Desde un punto de vista histórico, se había pensado especialmente en las violaciones de los privilegios diplomáticos — la causa solo sería enjuiciable por los tribunales federales de los Estados Unidos en cuanto que Estado anfitrión, mostrando así el debido respeto al Estado acreditado ${ }^{116}$ —. Al principio esta ley se aplicó muy excepcionalmente, pero su uso se reanimó en los años ochenta del pasado siglo ${ }^{117}$. En base a ella, los tribunales americanos comenzaron a admitir demandas de ciudadanos extranjeros reclamando a empresas extranjeras indemnización por lesiones de los derechos humanos producidas en el extranje-

remiten a una versión anterior de esta exigencia SKInNER/McCorquodale/De SchutTer/Lambe, Third Pillar [n. $\left.\left.{ }^{\circ} 110\right], 29\right)$. El Comisionado especial de Naciones Unidas para los derechos humanos y las empresas, J. RUGGIE, rechazó en su primer informe de 2007 una obligación jurídica general (Report of the Special Representative of the Secretary-General on the issue of human rights and transnational corporations and other business enterprises, John Ruggie - Addendum 1: State responsibilities to regulate and adjudicate corporate activities under the United Nations core human rights treaties: an overview of treaty body commentaries, UN-Dok A/ HRC/4/35/Add. 1 de 13.2.2007, ap. 81 y ss.). También el informe de RugGIE de 2011 subraya en el primer principio fundamental que los Estados están obligados a proteger a los ciudadanos frente a las vulneraciones de los derechos humanos realizadas por las empresas, pero solo «within their territory and/or jurisdiction» (Report of the Special Representative of the Secretary-General on the issue of human rights and transnational corporations and other business enterprises, John Ruggie - Guiding Principles on Business and Human Rights: Implementing the United Nations «Protect, Respect and Remedy» Framework, UN-Dok A/HRC/17/31, 21.3.2011, 6 y ss.). A la luz de este informe, asumido por el Comité de Derechos Humanos de las Naciones Unidas (UN-Menschenrechtsrat, Human rights and transnational corporations and other business enterprises, UN-Dok A/HRC/RES/17/4 v. 6.7.2011, 2), las Declaraciones de la Comisión del Pacto Social ya no se conciben como confirmación de una obligación jurídica estricta, sino como una exigencia de política del Derecho, al margen de que sean un mero instrumento de ayuda interpretativa.

113 A diferencia del asunto Google tratado en el anterior punto IV.2, en este caso la democracia no fracasa solo de manera puntual; entre el Estado potencialmente obligado a proteger y la ciudadanía necesitada de protección falta desde el principio un vínculo democrático.

114 Todavía se discute si las empresas (más allá del ius cogens internacional) están o pueden estar vinculadas directamente a los derechos humanos, véase A. Peters, Jenseits der Menschenrechte, 2014, 90 y ss., así como A. Clapham (dir.), Human Rights and Non-State Actors, 2013; hay de momento pocas perspectivas de que los Estados se pongan de acuerdo en imponer tales vinculaciones en los Tratados, véase PETERs, loc. cit., 92.

11528 U.S.C. $\$ 1350$. Esta ley contiene una sola disposición: «The district courts shall have original jurisdiction of any civil action by an alien for a tort only, committed in violation of the law of nations or a treaty of the United States.»

116 Sobre este fondo histórico M. STÜRNER, «Die territorialen Grenzen der Human Rights Litigation in den USA», JZ 2014, 13 y ss.

117 El caso clave es Filártiga v. Peña-Irala, 630 F.2d 876 (2d Cir. 1980); sobre el desarrollo ulterior STÜRNER, «Human Rights Litigation» (n. $\left.{ }^{\circ} 116\right), 16$ y ss. 
ro $^{118}$. A los tribunales les bastó con un mínimo punto de conexión, por ejemplo la existencia en los Estados Unidos de una pequeña oficina de la empresa, para reconocer su jurisdicción frente a los demandados ${ }^{119}$.

Muchos Estados consideraron irrespetuosa esta jurisprudencia, sobre todo los Estados de origen de las empresas ${ }^{120}$ - mayoritariamente europeos- y los Estados anfitriones que cooperaban con ellas y a los cuales la condena también afectaba indirectamente ${ }^{121}$. Surgieron dudas acerca de si el Alien Tort Statute cubría suficientemente una jurisprudencia de este tipo ${ }^{122}$; incluso hubo jueces a quienes les pareció que, simulando a Lohengrin, esta jurisprudencia emergía para proteger los derechos humanos sin que fuera lícito preguntarle de dónde procedían sus poderes ${ }^{123}$. Recientemente también el Tribunal Supremo ha definido las fronteras de esta jurisprudencia y ha recordado la presunción de rango constitucional que niega la jurisdicción extraterritorial ${ }^{124}$.

La ausencia de Lohegrin encuentra consuelo en Europa, porque tiene aquí descendientes legales ${ }^{125}$ : los Estados de la Unión Europea y Suiza han creado, con

118 En el caso Wiwa v. Royal Dutch Petroleum Co., 226 F.3d 88 (2d Cir. 2000), por ejemplo, ciudadanos nigerianos reclaman indemnizaciones por las vulneraciones de derechos humanos realizadas en Nigeria por la empresa europea Shell; véase también Presbyterian Church of Sudan v. Talisman Energy, Inc., 582 F.3d 244 (2d Cir. 2009); Sarei v. Rio Tinto, PLC, 671 F.3d $736\left(9^{\text {th }}\right.$ Cir. 2011).

119 Véase el caso Wiwa v. Royal Dutch Petroleum Co., 226 F.3d 88 (2d Cir. 2000).

120 Confróntese por ejemplo Brief of the Governments of the United Kingdom of Great Britain and Northern Ireland and the Kingdom of the Netherlands as Amici Curiae in Support of Neither Party, Kiobel v. Royal Dutch Petroleum Co., 133 S. Ct. 1659 (2013); Brief of The Federal Republic of Germany as Amicus Curiae in Support of Respondents, Kiobel v. Royal Dutch Petroleum Co., 133 S. Ct. 1659 (2013); al respecto D. I. BAKER «Extraterritoriality and the Rule of Law: Why Friendly Foreign Democracies Oppose Novel, Expansive U.S. Jurisdiction Claims by Non-Resident Aliens Under the Alien Tort Statute», Md. J. Int'l L. 2013, 42; sobre la oposición europea a la jurisdicción extraterritorial también en otros asuntos véase A. REINISCH, «The Changing International Legal Framework for Dealing with Non-State Actors», en P. Alston (dir.), Non-State Actors and Human Rights, 2005, 37 (57).

121 Esto es un mecanismo bien conocido en el supuesto en que dos actores provocan conjuntamente la vulneración de derechos humanos. Los tribunales imputan al que les resulta accesible y le atribuyen toda la responsabilidad, como se atribuye al Estado la actuación de las concesionarias, o el procesamiento de datos por parte de Google Inc. se considera en «el marco de la actividad» de Google Spain; en el caso de las empresas transnacionales, se atribuye la responsabilidad por las acciones del Estado a su cómplice privado, porque a veces solo se puede demandar a las empresas, véase al respecto Reinisch, «Non-State Actors» (n. $\left.{ }^{\circ} 120\right), 65$, que da cuenta del caso Myanmar, donde las víctimas demandaron ante los tribunales de los Estados Unidos a la empresa Unocal como cómplice del citado Estado, que no podía ser directamente llevado a los tribunales por gozar de inmunidad.

122 Por ejemplo J. M. SweEney, «A Tort Only in Violation of the Law of Nations», Hastings International and Comparative Law Review 1995, 445; A. Bradley/J. L. Goldsmith, «The Current Illegitimacy of International Human Rights Litigation», Fordham L. Rev. 1997, 317; en contra de esta crítica R. KNOwLES, «A Realist Defense of the Alien Tort Statute», Wash. U. L. Rev. 2011, 1117; STürner, «Human Rights Litigation» (n. $\left.{ }^{\circ} 116\right), 13,22$.

123 Juez Friendly en la sentencia IIT v. Vencap Ltd., 519 F.2d 1001, 1015 (2d Cir. 1975).

124 Kiobel et al. v. Royal Dutch Petroleum et al., 569 U.S. (2013) = 133 S. Ct. 1659 (2013); con una visión crítica de esta decisión y sus consecuencias STÜRNER, «Human Rights Litigation» (n. $\left.{ }^{\circ} 116\right), 17$ y ss.

125 Para los detalles de lo que sigue véase R. GraBOsCH, «Rechtsschutz vor deutschen Zivilgerichten gegen Beeinträchtigungen von Menschenrechten durch transnationale Unternehmen», en R. Nikol/T. Bernhard/N. Schniederjahn (dir.), Transnationale Unternehmen und Nichtregierungsorganisationen im Völkerrecht, 2013, 69. 
una base jurídica sólida, una jurisdicción competente ${ }^{126}$ ante la que pueden reclamarse indemnizaciones por daños frente a las empresas establecidas en ellos, también en relación con sus actividades en el extranjero ${ }^{127}$. Esas causas son juzgadas por principio conforme al derecho del Estado en el que se han producido los daños ${ }^{128}$, esto es, el Estado anfitrión de la empresa, pero con dos excepciones importantes: son inaplicables las normas que claramente van en contra del orden público del Estado que ejerce la jurisdicción ${ }^{129}$ y, a la inversa, son aplicables las normas de dicho Estado que éste considera decisivas para garantizar el interés público ${ }^{130}$. En conjunto, el Estado de origen de la empresa puede compensar los más graves déficits de regulación y control del Estado anfitrión ${ }^{131}$.

Las víctimas de estas vulneraciones de derechos humanos afrontan una trabajosa lucha por sus derechos ${ }^{132}$ : los procesos tienen lugar en el extranjero, duran muchos años, son enormemente caros y la carga de la prueba supone un lastre, dado que las malas condiciones de seguridad que suelen darse en el Estado donde se produce la lesión hacen difícil obtener medios de prueba, en especial movilizar a los testigos ${ }^{133}$. Además, las empresas, a tenor de su forma de consorcio, constru-

126 Art. 2 del Reglamento del Consejo 44/2001/CE relativo a la competencia judicial, el reconocimiento y la ejecución de resoluciones judiciales en materia civil y mercantil de 22 de diciembre de 2000. Suiza y los restantes Estados integrados en la EFTA han hecho suyo el régimen de este Reglamento a través del Acuerdo de Lugano; respecto a Suiza véase art. 2 y 21 IPRG. De acuerdo con el citado Reglamento, los tribunales no pueden rechazar su competencia argumentando que otro tribunal es más idóneo (Tribunal de Justicia, Owusu v. N. B. Jackson u.a., Rs. C-281/02, Slg. 2005, I-1383, ap. 46). Apoyándose en este forum non conveniens, los tribunales americanos han derivado en ocasiones a los demandantes hacia los Estados anfitriones de las empresas, alegando que los daños se habían producido en su territorio. Pero en estos Estados la demanda casi nunca se acababa planteando, al no haber expectativa alguna de que fuera atendida razonablemente o incluso porque el demandante habría tenido que contar con sufrir persecución; así que de facto se queda sin tutela, véase Skinner/McCorquodale/De SchutTer/Lambe, Third Pillar (n. $\left.{ }^{\circ} 110\right), 39$ y ss.

127 Algunos Estados admiten también reclamaciones de daños cuando la empresa, pese a carecer en su territorio de una sucursal, dispone allí de patrimonio, por ejemplo en Alemania ( $\$ 23$ ZPO) y Austria ( 99 JN). En Suiza, una empresa puede ser demandada por daños cuando no cabe esperar en otro Estado un proceso con todas las garantías y la acción tiene alguna relación con Suiza, es el llamado forum necessitatis, art. 3 IPRG. La Comisión realizó una propuesta para reformar en tal sentido el Reglamento 44/2001/CE, que, sin embargo, no fue aceptada COM (2010) 748, 14.12.2010, véase el art. 26.

128 Art. 4 del Reglamento (CE) n. ${ }^{\circ} 864 / 2007$ del Parlamento europeo y del Consejo de 11 de julio de 2007 relativo a la ley aplicable a las obligaciones extracontractuales («Roma II»). Una excepción está establecida en el art. 7 para los daños medioambientales.

129 Art. 26 Roma II.

130 Las llamadas «leyes de policía», art. 16 Roma II.

131 A diferencia del Alien Tort Satute, la prentensión de indemnización no puede medirse conforme a la concepción europea directamente a partir de los principios de derecho internacional, véase STÜRNER, «Human Rights Litigation» (n. ${ }^{\circ}$ 116), 22. Los estándares de derechos humanos podrían aplicarse mediatamente en el marco del control de orden público o como normas de policía, Grabosch, «Rechtsschutz» (n. ${ }^{\circ}$ 125), 84 y ss., y también O. De Schutter, «The Accountability of Multinationals for Human Rights Violations in European Law», en Alston (n. ${ }^{\circ} 121$ ), 227 (274 y ss.).

132 Véase sobre lo que sigue SKInNer/MCCorquOdale/De SchutTer/Lambe, Third Pillar (n. ${ }^{\circ} 110$ ), 61 y ss.

133 Estos problemas de prueba disminuyen cuando un Estado califica las vulneraciones de derechos humanos como ilícitos penales y asume así la carga de la prueba; esto, sin embargo, sucede excepcionalmente, 
yen una maraña inabarcable de entidades con diversas funciones, dificultando el levantamiento del velo. Y más difícil aún para la víctima es demostrar que, por ejemplo, una sociedad matriz con sede en la Unión Europea está involucrada en la vulneración de derechos humanos de una de sus sucursales en Nigeria.

Todo esto explica el escaso porcentaje de éxito de estas reclamaciones de daños tanto en Europa como en Estados Unidos ${ }^{134}$. Pero las demandas se plantean, precisamente porque proporcionan al asunto relevancia mediática ${ }^{135}$. Así que el «tercer poder» solo se pondrá en funcionamiento para activar al «cuarto poder», y este movilizará a los consumidores: si estos, por solidaridad con la víctima de la vulneración de los derechos humanos, dejan de consumir ${ }^{136}$, pueden hacer que una empresa pierda mucho dinero en poco tiempo — incluso cuando no han incurrido en ninguna culpabilidad ${ }^{137}$ —. Se trata de un proceso descentralizado de protección de los derechos humanos que discurre totalmente al margen del Estado.

Entre estos dos polos extremos —el interminable proceso judicial y el juicio inmediato de la sociedad civil — hallamos toda una variedad de instrumentos ${ }^{138}$.

porque a menudo falta la competencia, los recursos son escasos y el caso demasiado complejo, pero también porque la responsabilidad penal de las empresas no está prevista en muchos Estados, SKINNER/MCCORQUODale/De SChutTer/Lambe, Third Pillar (n. $\left.{ }^{\circ} 110\right), 47$ y ss.

134 Se han planteado hasta el momento 180 demandas contra empresas de acuerdo con el Alien Tort Statute, pero solo una pequeña parte termina con una condena de la empresa (2) o con un acuerdo entre las partes (13): M. D. Goldhaber, «Corporate Human Rights Litigation in Non-U.S. Courts: A Comparative Scorecard», UC Irvine Law Review 2013, 127 (128).

135 J. C. Drimmer/S. R. Lamoree, «Think Globally, Sue Locally: Trends and Out-of-Court Tactics in Transitional Tort Actions», Berkeley J. Int'l Law 2011, 456 (488).

136 Los estudios demuestran que cada vez más consumidores valoran que los productos se hayan elaborado respetando pautas éticas; los impulsos a la ética en el consumo se siguen encontrando en la política, pero también cada vez más en las oenegés y la economía, véase Otto Group Trendstudie 2013. 4. Studie zum etbischen Konsum, 2013, 8 ss., www.ottogroup.com/media/docs/de/trendstudie/1_Otto_Group_Trendstudie_2013.pdf (31.10.2014).

137 Agunos informes exageran, como pudo comprobar la empresa Shell en 1995, que planeaba vaciar en el mar del norte la plataforma de crudo «Brent Spar». Para evitarlo, la organización medioambiental Greenpeace inició un boicot con repercusión mediática. Como las gasolineras de Shell empezaron a padecer fuertes pérdidas, el conglomerado cambió la posición y renunció a arrojar el crudo al mar. Sin embargo, como luego se supo, Greenpace había sobredimensionado claramente el riesgo, en especial porque «Brent Spar» contenía solo una fracción de los residuos que se le suponían, véase «Versenkt die Shell», SPIEGEL ONLINE, 19.6.1995; R. LUYKEN, «Die Protest-Maschine», ZEIT ONLINE, 6.9.1996; REINISCH en Alston (n. $\left.{ }^{\circ} 130\right), 48$.

138 Junto a los instrumentos citados a continuación están, por ejemplo, UN Guiding Principles for Business and Human Rights (Report of the Special Representative of the Secretary-General on the issue of human rights and transnational corporations and other business enterprises [n. ${ }^{\circ} 12$ ]); también las Normas-ISO 26000 sobre responsabilidad social (ISO 26000:2010 — Principios sobre la responsabilidad social de las organizaciones); en detalle por ejemplo N. JäGERs, «UN Guiding Principles on Business and Human Rights: Making Headway Towards Real Corporate Accountability?», Netherlands Quaterly of Human Rights 2011, 159; Peters, Jenseits der Menschenrechte (n. ${ }^{\circ}$ 114), 92 y ss.; M. Kaltenborn/J. Norpoth, "Globale Standards für soziale Unternehmensverantwortung», $R i W$ 2014, 402. La Unión Europea también coloca sus propios acentos; así, la Comisión Europea exigió a todas las grandes empresas europeas que antes del año 2014, en sus estrategias de responsabilidad social, se comprometieran a atenerse a los principios de la OCDE sobre las empresas multinacionales, el «Global Compat» de las Naciones Unidas o la norma ISO 26000 sobre responsabilidad social: Comunicación de la Comisión al Parlamento Europeo, al Consejo, al Comité Econó- 
Por ejemplo, la OCDE, mediante unos principios codificados ${ }^{139}$, recomienda a las empresas que respeten determinados estándares de derechos humanos. A su vez, los gobiernos nacionales establecen oficinas de contacto en las que se realizan procedimientos de mediación para atender a aquellas personas que denuncian la vulneración de esos principios. Se trata de procedimientos no tan largos ni costosos, aunque tampoco tan espectaculares como los procesos judiciales; quizá por eso se usan con más intensidad en Europa que en los Estados Unidos ${ }^{140}$.

Por otro lado, el «Global Compact» de las Naciones Unidas se dirige directamente a las empresas ${ }^{141}$, a las que exige reconocer y aplicar determinados principios $^{142}$. Quien se incorpora gana en imagen, pero debe dar cuenta anualmente de los avances que logra en su aplicación. Si no cumple, al cabo de un año se la señala como «non communicating» — que es una mancha fatal en el siglo XxIy, después de un año más, resulta excluida ${ }^{143}$. Este concepto de la autovinculación ya no trata de desvelar escándalos, sino que da en primer lugar la palabra a las empresas. Si callan, padecerán una pérdida de reputación. A día de hoy, 8.000 empresas de 145 países se han sumado al «Global Compact» ${ }^{144}$.

La autovinculación blanda, sin embargo, también puede fraguar hasta convertirse en un sólido imperativo. Un buen ejemplo se produce en el derecho de la competencia: quien incumpla sistemáticamente un código de conducta al que se ha sometido voluntariamente y del que hace propaganda ${ }^{145}$ debe contar en Europa con que sus competidores o las asociaciones de consumidores le denunciarán por competencia desleal ${ }^{146}$.

mico y Social Europeo y al Comité de las Regiones, Estrategia renovada de la UE para 2011-2014 sobre la responsabilidad social de las empresas de 25.10.2011 Com(2011) 681 final.

139 Principios OCDE sobre empresas multinacionales, 2011, www.oecd.org/investment/ mne/48808708.pdf (31.10.2014).

$140 \mathrm{La}$ base de datos de la OCDE señala 168 procedimientos ante las oficinas nacionales de contacto de los Estados de la Unión y 10 en Suiza, pero solo 37 en Estados Unidos, véase mneguidelines.oecd.org/database/ (31.10.2014); sobre las posibles causas J. WOUTERS/C. RYNGAERT, «Litigation for overseas corporate human rights abuses in the European Union: The Challenge of Jurisdiction», The Geo. Wash. Int'l L. Rev. 2009, 939 (972 y ss.).

141 En detalle para el Global Compact, www.unglobalcompact.org/Languages/german/index.html (31.10.2014); R. G. STEINHARDT, «Corporate Responsibility and the International Law of Human Rights: The New Lex Mercatoria», en P. Alston (n. ${ }^{\circ} 121$ ), 177 (206 y ss.); A. Rasche/S. WAdDock/M. McINTOSH, «The United Nations Global Compact: Retrospect and Prospect», Business E Society 2013, 6.

142 De acuerdo con el principio número 1, las empresas deben apoyar y respetar la protección de los derechos humanos; de acuerdo con el principio 7, deben seguir el principio de precaución respecto al medio ambiente; y, de acuerdo con el principio 10, deben renunciar a todo tipo de corrupción.

143 Más información en www.unglobalcompact.org/docs/communication_on_progress/COP_Policy. $\operatorname{pdf}(31.10 .2014)$.

144 En detalle www.unglobalcompact.org/ParticipantsAndStakeholders/index.html (31.10.2014).

145 La praxis de los negocios debe ser adecuada, tomando en cuenta todas las circunstancias de hecho del caso concreto, para conducir al consumidor medio a una decisión comercial que él no hubiera tomado por sí mismo.

146 Art. 6. 2 b) de la Directiva 2005/29/CE del Parlamento Europeo y del Consejo de 11 de mayo de 2005, de 11 de mayo de 2005 relativa a las prácticas comerciales desleales de las empresas en sus relaciones 
¿Qué nos muestran estos desarrollos? Cuando los gobiernos se ligan a actores económicos muy poderosos, no protegen a sus ciudadanos, y los tribunales de estos Estados tampoco ayudan, la garantía de los derechos humanos se descentraliza y complica. Conduce a una actuación en paralelo de diversos actores —otros Estados, organizaciones internacionales, onegés, competidores, medios de comunicación y consumidores-, cada uno de los cuales utiliza los instrumentos que tiene a su disposición. La coacción estatal es solo uno entre otros, y no siempre el de máxima eficacia. Cobra cada vez más importancia como instrumento de poder la información, que en manos de la sociedad civil puede convertirse en una espada afilada.

\section{Potencias extranjeras}

Las cosas se complican si quien perturba el derecho fundamental no es un particular, sino un Estado extranjero. La jurisprudencia y la mayoría de la doctrina entienden que en estas situaciones el Estado debe proteger a sus ciudadanos ${ }^{147}$; tal obligación de protección, sin embargo, ha de luchar con un problema de fondo: a diferencia de los particulares, el Estado extranjero está con el Estado protector en relación de coordinación y no de subordinación ${ }^{148}$. Por eso el Estado garante no puede evitar la lesión de los derechos fundamentales sencillamente de modo coactivo y debe sujetar con otros medios al Estado al que se le imputa la vulneración ${ }^{149}$. Al respecto, la perspectiva mayoritaria señala que le resulta legítimo tener en cuenta que medidas demasiado enérgicas de protección podrían lastrar sus relaciones diplomáticas con el otro Estado ${ }^{150}$. De ahí que algunas conductas que

con los consumidores en el mercado interior, que modifica la Directiva 84/450/CEE del Consejo, las Directivas 97/7/CE, 98/27/CE y 2002/65/CE del Parlamento Europeo y del Consejo y el Reglamento (CE) n. ${ }^{\circ}$ 2006/2004 del Parlamento Europeo y del Consejo («Directiva sobre las prácticas comerciales desleales»); traspuesta en el $\S 5.1$ Z. 6 UWG; $\S 2.3$ de la ley austríaca de competencia desleal UWG; véase J. WoUTers/L. Chanet, «Corporate Human Rights Responsibility: A European Perspective», Northwestern Journal of International Human Rights 2008, 262 (287 y ss.).

147 Szczekalla, Schutzpflichten (n. ${ }^{\circ}$ 31), 133 y ss., 283 y ss., 437 y ss.; J. Dietlein, Schutzpflichten (n. $\left.{ }^{\circ} 41\right), 122$ y ss.; así como en la bibliografía citada en la nota 152; con una visión escéptica y bibliografía sobre la posición opuesta H. Dreier, en Dreier (n. $\left.{ }^{\circ} 11\right)$, prefacio a art. 1, ap. 104.

148 J. IsEnSEE, «Abwehrrecht und Schutzpflicht», HStR IX, 3. ed. 2011, § 191 ap. 208.

149 Sobre las posibles reacciones contra las vulneraciones de Derecho internacional T. GIEGERICH, «Verfassungsgerichtliche Kontrolle der auswärtigen Gewalt im europäisch-atlantischen Verfassungsstaat: Vergleichende Bestandsaufnahme mit Ausblick auf die neuen Demokratien in Mittel- und Osteuropa», Zä̈RV 1997, 409 (473 y ss.), y en especial frente a las operaciones de información T. STEIN/T. MARAUHN, «Völkerrechtliche Aspekte von Informationsoperationen», Zä̈RV 2000, 1 (26 y ss.).

150 Sobre la flexibilidad del control en este ámbito, SzCzeralla, Schutzpflichten (n. ${ }^{\circ} 31$ ), 285 y ss., 451 y ss.; V. RöBen, Außenverfassungsrecht, 2007, 203 y ss. Apoyados en el amplio margen de discrecionalidad, en ocasiones se rechazan incluso por principio los deberes de intervención estatal; así, por ejemplo, W. Ewer/T. Thienel, «Völker-, unions- und verfassungsrechtliche Aspekte des NSA-Datenskandals», NJW 2014, 30 (35), dicen que el Gobierno federal alemán, con referencia al escándalo de la NSA, no está obligado 
en manos de particulares consideramos como distorsiones del sistema de derechos, sin embargo, las aceptemos aquí como parte del sistema. Por lo demás, es difícil denunciar el déficit de protección frente a un Estado extranjero. Los tribunales, como hemos visto, están en condiciones de suplir la inexistencia de normas de protección ${ }^{151}$, pero no de emitir notas de protesta, entablar negociaciones con otros Estados, presentar demandas contra ellos o denunciar tratados.

En lugar de esperar a la protección en este ámbito, merece la pena considerar si no cabe enfrentarse de antemano a la propia vulneración de los derechos fundamentales. Un buen ejemplo es el escándalo de la National Security Agency (NSA), que ha generado una producción bibliográfica usualmente incluida bajo la rúbrica de los deberes de protección ${ }^{152}$. Sin embargo, desde que Edward Snowden destapó en junio de 2013 que el servicio secreto de los Estados Unidos había intervenido masivamente las comunicaciones en Europa ${ }^{153}$, los Estados europeos no han tomado ninguna medida significativa de protección ${ }^{154}$.

Los ciudadanos europeos no pueden proceder directamente contra el vulnerador, esto es, los Estados Unidos, puesto que el ordenamiento jurídico de este país no prevé derechos ni acciones de protección en favor de las personas que son espiadas en el extranjero ${ }^{155}$. No obstante, el servicio secreto americano no desplie-

«a poner en funcionamiento y menos aún a agotar las posibilidades de actuación internacional que se le reconocen». En sentido contrario y de modo acertado W. HofFMANN-RiEM, «Freiheitsschutz in den globalen Kommunikationsinfrastrukturen», JZ 2014, 53 (62), para quien el Gobierno federal debe tener margen de actuación acerca de cómo proteger, pero no sobre la posibilidad misma de emprender actuaciones de protección; para una visión general DiETLEIN, Schutzpflichten (n. $\left.{ }^{\circ} 31\right), 123$ : «Un ámbito de discrecionalidad más amplio no significa ausencia de vínculos».

151 Más arriba II.3. y n. ${ }^{\circ} 106$.

152 Por ejemplo A. Peters, «Surveillance Without Borders? The Unlawfulness of the NSA-Panopticum, Part II», EJIL: Talk! 2013, www.ejiltalk.org/author/anne-peters/ (31.10.2014); EwER/THIENEL, «NSA-Datenskandal» (n. $\left.{ }^{\circ} 150\right)$, 34 y ss.; HofFMANN-RIEM, «Freiheitsschutz» (n. $\left.{ }^{\circ} 150\right), 56$ y ss.; S. SCHMAHL, «Effektiver Rechtsschutz gegen Überwachungsmaßnahmen ausländischer Geheimdienste?», JZ 2014, 220 (221, 226 y ss.); P. SzCZEKALlA, «Sicherung grund- und menschenrechtlicher Standards gegenüber neuen Gefährdungen durch private und ausländische Akteure», DVBl 2014, 1108 (1110 y ss., 1113); véanse también las posiciones de W. Hoffmann-Riem (15 y ss.) y H.-J. Papier (9 y ss.) en las audiencias de la Comisión de investigación sobre la NSA de 22.5.2014, localizabes en www.bundestag.de/bundestag/ausschuesse18/ ua/1 untersuchungsausschuss/-/280848 (31.10.2014).

153 Sobre estos descubrimientos, de entre la masiva bibliografía, en especial G. GreEnWaLd, Die globale Überwachung, 2014; M. RosenbaCH/H. STARK, Der NSA-Komplex, 2014.

154 Cuan amplio es el espectro de medidas posibles se ve en el exhaustivo catálogo de exigencias que el Parlamento Europeo dirigió a los Estados Unidos y a los Estados de la Unión: Resolución del Parlamento Europeo sobre el programa de vigilancia de la NSA, los órganos de vigilancia en diversos Estados miembros y su impacto en los derechos fundamentales de los ciudadanos de la UE y en la cooperación transatlántica en materia de justicia y asuntos de interior (2013/2188(INI)).

155 P. WitTMAnN, Der Schutz der Privatsphäre vor staatlichen Überwachungsmaßnahmen durch die US-amerikanische Bundesverfassung, 2014, 698 y ss., 789, 797 y ss.; véase el Report on the Findings by the EU Co-chairs of the ad hoc EU-US Working Group on Date Protection, de 27.11.2013, punto 5, en el que se señala que los ciudadanos de la Unión no pueden obtener ninguna información sobre los datos que se han recabado y procesado en el marco del programa de vigilancia de los Estados Unidos; tampoco existen remedios para corregir o borrar información, ni remedios administrativos o judiciales. Sin duda, los Estados Unidos han ratificado el PIDCP, que reconoce a toda persona, incluido en el extranjero, el derecho a la protección de su 
ga en solitario su vigilancia mundial, necesita de numerosas ayudas: por ejemplo, la de cuatro Estados con los que está estrechamente vinculado, entre ellos el Reino Unido ${ }^{156}$, y también la de particulares, como la totalidad de las grandes empresas prestadoras de servicios de internet: Google, Facebook, Microsoft, YouTube, etc. ${ }^{157}$, a través de cuyos servidores discurre gran parte del tráfico mundial de datos. La regla aplicada a la administración a través de particulares, a Google Spain y a las empresas transnacionales también podría valer en estos casos: si quien ha vulnerado el derecho fundamental está fuera de nuestro alcance, se ha de perseguir a quien le ayuda. En realidad, dos procedimientos pendientes lo están intentando.

El primero es una demanda ante el Tribunal Europeo de Derechos Humanos invocando que resulta contraria al Convenio la vigilancia del servicio secreto británico, tanto dentro del Reino Unido como en las comunicaciones con el extranjero $^{158}$. Si el TEDH acepta controlar este espionaje con el CEDH como criterio ${ }^{159}$

vida privada (art. 17). Pero los Estados Unidos no se han sometido aquí al procedimiento de las demandas individuales. De todos modos, el Comité de derechos humanos de las Naciones Unidas, en el marco de los procesos informativos sobre los Estados (art. 40 PIDCP), ha mostrado su preocupación por el hecho de que las medidas de vigilancia de la NSA vulneran el PIDCP; el Comité reconoce, no obstante, que la Presidential Policy Directive (PPD-28) supone una cierta mejora para los no estadounidenses; pero denuncia al mismo tiempo que las personas lesionadas siguen careciendo de protección jurídica efectiva: Human Rights Committee Concluding observations on the fourth report of the United States of America, adoptado por el Comité en su sesión 110 (10-28 de marzo de 2014), ap. 22.

156 Los servicios secretos de los Estados Unidos, el Reino Unido, Canada, Australia y Nueva Zelanda componen el llamado grupo «Five Eyes»: se complementan perfectamente dada su situación geopolítica; los une además la lengua y una comprensión compartida del derecho: T. WEICHERT, «Globaler Kampf um digitale Grundrechte», Kritische Justiz 2014, 123 y ss. Sobre esta cooperación y otros cooperantes de la NSA, entre los que parecen estar por ejemplo Alemania, Austria y Suiza, véase Greenwald, Überwachung (n. ${ }^{\circ} 153$ ), 174 y ss., en especial 180 .

157 Con más detenimiento sobre estas cooperaciones y los programas de vigilancia GREENWALD, $\ddot{U}$ berwachung (n. $\left.{ }^{\circ} 153\right), 151$ y ss. Una panorámica sobre el programa establecido por la NSA y el GCHQ podemos verlo en P. BEUTH, «Alles Wichtige zum NSA-Skandal», ZEIT ONLINE (en actualización), www. zeit.de/digital/datenschutz/2013-10/hintergrund-nsa-skandal/komplettansicht (30.10.2014).

158 La demanda fue planteada el 4.9.2013 por tres oenegés con sede en Londres (Big Brother Watch, English PEN, Open Rights Group) y una especialista en vigilancia técnica residente en Alemania, y ha sido registrada ante el TEDH con el número 58170/13. En especial se alega que el GCHQ recibió y trató sin habilitación legal información de los servicios secretos extranjeros, y que en virtud de una base legal muy vaga intervino comunicaciones extranjeras. Después de que el 9.1.2014 el TEDH, entre otras cosas, preguntara sobre el agotamiento de las vías jurisdiccionales nacionales (EuGRZ 2014, 122 [125]), se decidió suspender el procedimiento el 11.4.2014, hasta que no se cerrase el procedimiento interno iniciado por las reclamantes ante el Investigatory Powers Tribunal, que decide sobre las demandas contra los servicios secretos; si esta vía no se mostrata efectiva, entonces se seguiría con el procedimiento ante el TEDH.

159 Se duda de que el CEDH sea aplicable a este caso, puesto que el art. 1 asegura derechos y libertades solo para las personas que se encuentran bajo la jurisdicción de los Estados que han ratificado el Convenio. Indiscutiblemente, un Estado también puede tener jurisdicción en el extranjero; el TEDH lo ha confirmado hasta ahora solo cuando se trata del desempeño de actividades estatales por parte de autoridades diplomáticas y consulares, cuando un Estado tiene el control completo sobre un territorio (por ejemplo en una ocupación militar) o cuando controla a determinadas personas, por ejemplo al detenerlas o internarlas (véase G. Thallinger, Grundrechte und extraterritoriale Hoheitsakte, 2008, 113 y ss., 179 y ss.). Apoyándose en esta jurisprudencia, S. TALMON, en su exposición ante la Comisión de Investigación sobre la NSA, 9 
y - esto es una cuestión distinta- considera que vulnera el Convenio ${ }^{160}$, entonces las comunicaciones vía fibra óptica entre Estados Unidos y el Reino Unido ya no podrían ser controladas por la NSA en la misma medida en que hoy lo hace.

Un segundo proceso está pendiente ante el Tribunal de Justicia. Compromete a Facebook, que ofrece una importante ayuda a la NSA enviando datos de sus usuarios a los Estados Unidos, donde, tal y como censuró el demandante en el litigio principal ${ }^{161}$, no existe seguridad para estos datos; esto contradice el artículo 25.6 de la Directiva de protección de datos. El organismo irlandés encargado de la protección de datos consideró la reclamación como «una frivolidad» ${ }^{162}$, pues la Comisión Europea, en el llamado asunto «Safe-Harbor», ya había señalado en el año 2000 que los Estados Unidos ofrecían una protección suficiente de los da-

y ss. (www.bundestag.de/bundestag/ausschuesse18/ua/1 untersuchungsausschuss/-/280848, 31.10.2014) niega la aplicación del Convenio a la medidas de vigilancia que despliega el GCHQ en el extranjero, incluso respecto a las medidas que el GCHQ ejecuta en el país con las que vigila a personas que se hallan en el extranjero. En ambos casos, el GCHQ no ejerce un control completo sobre un territorio extranjero ni un control físico sobre personas. Contra la aplicación del Convenio en la vigilancia global se alega también que daría legitimación a millones, incluso a miles de millones de personas (TALmon, 9, 11). Si se llevara este segundo argumento a sus últimas consecuencia, significaría que el CEDH no sería aplicable cuando un Estado cometiera vulneraciones masivas de los derechos y libertades, lo que, obviamente, es poco convincente. Por otro lado, se ha de recordar que, sin plantearse problemas procesales, el TEDH admitió demandas presentadas por dos oenegés con sede en Dublín contra medidas de vigilancia de las autoridades británicas (EGMR 1.7.2008, Liberty u.a. v. UK, Appl. 58243/00, ap. 55). Esto hace pensar que el TEDH considera aplicable el CEDH cuando un Estado espía a personas en el extranjero (H. P. Aust, «Stellungnahme für den NSA-Untersuchungsausschuss», 11, www.bundestag.de/bundestag/ausschuesse18/ua/ 1 untersuchungsausschuss/-/280848, 31.10.2014). Respecto de las medidas de espionaje que un Estado realiza en un territorio extranjero carecemos, sin embargo, de una jurisprudencia concluyente, pues las decisiones del TEDH que se han dictado hasta ahora se refieren al uso de armas en territorio extranjero; un control tan intenso como este no puede obviamente alcanzarse con medidas de espionaje (Aust, 12). En mi opinión, este tipo de espionaje provoca un «control virtual», independientemente de los medios técnicos utilizados y del lugar desde el que se realiza. Cualquier otra interpretación solo serviría para abrir al Estado nuevos caminos para separase mediante técnicas refinadas de la vinculación a los derechos fundamentales. Tal y como ha expuesto el TEDH en el caso Issa, el art. 1 no debe interpretarse de tal modo que permita a las altas partes contratantes vulnerar el convenio en territorio extranjero mediante actuaciones que, sin embargo, le están prohibidas en su propio territorio (EGMR 16.11.2004, Issa u.a. v. Türkei, Appl. 31821/96, ap. 71). En favor de una ampliación del concepto de control, incluyendo también un «virtual control», ya Peters, «Surveillance» (n. $\left.{ }^{\circ} 152\right)$; P. Margulies, «The NSA in Global Perspective: Surveillance, Human Rights, and International Counterterrorism», Fordham Law Review 82 (2014), 2137 (2150 y ss.); D. KORFF, «Stellungnahme zum NSA-Untersuchungsausschuss», 4, www.bundestag.de/ bundestag/ausschuesse18/ua/1 untersuchungsausschuss/-/280848, 31.10.2014; respecto a estas constelaciones de problemas también AUST, 13 y ss.; también afirma la aplicación del CEDH SCHMAHL, «Rechtsschutz» (n. ${ }^{\circ}$ 152), 227, que se apoya sin embargo en la aplicación analógica de la jurisprudencia del TEDH relativa a la extradición; también consideran aplicable el CEDH, aunque con cautelas, EwER/THIENEL, «NSA-Datenskandal» (n. $\left.{ }^{\circ} 150\right), 32$.

160 Escéptica respecto a la conformidad con el Convenio por ejemplo PETERs, «Surveillance» (n. ${ }^{\circ}$ 152); Ewer/Thienel, «NSA-Datenskandal» (n. ${ }^{\circ}$ 150), 33; D. KorfF, «Stellungnahme» (n. ${ }^{\circ}$ 159), 3; SCHMAHL, «Rechtsschutz» (n. ${ }^{\circ} 152$ ), 225.

161 El recurso se puede encontrar en www.europe-v-facebook.org/prism/facebook.pdf (31.10.2014)

162 El supuesto de hecho se describe en la cuestión planteada por el High Court of Ireland, 17.7.2014, Maximilian Schrems/Data Protection Commissioner, 2013/765JR, ap. 4, www.europe-v-facebook.org/ref_ ecj.pdf (31.10.2014). 
tos personales ${ }^{163}$. El Tribunal Supremo irlandés entendió, sin embargo, que desde aquella decisión se habían producido importantes novedades: la Carta de Derechos fundamentales había pasado a ser vinculante; el Tribunal de Justicia había manifestado que un almacenamiento de los datos masivo e infundado vulneraba la Carta $^{164}$; y con las revelaciones de Snowden se había sabido que los Estados Unidos vigilaban las comunicaciones con el extranjero de forma masiva y sin la existencia de sospechas ${ }^{165}$. El Tribunal irlandés ha preguntado al Tribunal de Justicia $^{166}$ si todavía está vinculado a la decisión de la Comisión o si, a la luz de estas novedades, puede o incluso debe realizar sus propias averiguaciones sobre la seguridad de los datos en los Estados Unidos ${ }^{167}$. Con este procedimiento, el Tribunal de Justicia tiene la oportunidad de cerrar a la NSA un canal de información que le había abierto la Comisión mediante su decisión «Safe-Harbor»; que ella misma no haya cerrado antes esa vía ${ }^{168}$ no implica una violación del deber de protección $^{169}$, sino una injerencia prolongada en el tiempo frente a la que, si se considera injustificada, cabe defenderse.

La existencia de particulares que ayudan a los servicios secretos reactiva el papel de los consumidores, que podrían cambiarse a otro prestador de servicios de internet que no cooperara con el servicio secreto americano. Es un temor que

163 Decisión de la Comisión de 26 de Julio de 2000 con arreglo a la Directiva 95/46/CE del Parlamento Europeo y del Consejo, sobre la adecuación conferida por los principios de puerto seguro para la protección de la vida privada y las correspondientes preguntas más frecuentes, publicadas por el Departamento de Comercio de Estados Unidos de América DOUE L 215/2000, 7.

164 Tribunal de Justica 8.4.2014 (Gran Sala), Digital Rights Ireland und Seitlinger u.a., asuntos C-293/12 y C-594/12.

165 Cuestión prejudicial del High Court of Ireland (n. $\left.{ }^{\circ} 162\right)$, ap. 67 y ss.

166 Este procedimiento se ha registrado en el Tribunal de Justicia con el número C-362/14.

167 En Alemania y algunos otros Estados miembros, tal competencia de control en favor de la autoridad de protección de datos se acepta a veces (F. C. MAYER, «Mit Europarecht gegen die amerikanischen und britischen Abhöraktionen? Teil 1: NSA», VerfBlog 18.11.2013, www.verfassungsblog.de/mit-europarechtgegen-amerikanischen-und-britischen-abhoeraktionen-teil-1-nsa/, 31.10.2014), a veces se rechaza (A. SPIES, «Datenschutzbeauftragte: Keine «Genehmigungen» mehr zum USA-Datenexport nach Safe Harbor — ist das rechtlich möglich?», ZD-Aktuell 2013, 3691).

168 Se ha reclamado de la Comisión en múltiples ocasiones la suspensión de la decisión «Safe Harbor», por ejemplo en la conferencia de las autoridades alemanas de protección de datos (Comunicado de prensa de 24.7.2013, «Geheimdienste gefährden massiv den Datenverkehr zwischen Deutschland und außereuropäischen Staaten»), más tarde también por parte del Parlamento europeo (sesión de 12.3.2014 [n. ${ }^{\circ}$ 154], ap. 40). Hasta ahora, la Comisión solamente ha puesto «seriamente en cuestión [...] si los derechos de protección de datos de los ciudadanos europeos siguen estando protegidos [...] visto el amplio acceso de los servicios secretos a los datos que Safe-Harbor transfiere a los Estados Unidos». Al mismo tiempo formuló trece recomendaciones que deberían hacer más efectiva la regulación del Safe-Harbor, entre otras: «Es importante que la excepción de la seguridad nacional prevista en la decisión Safe-Harbor se utilice solamente cuando sea efectivamente necesaria o adecuada» (Comunicación de la Comisión al Parlamento Europeo y al Consejo sobre el funcionamiento del puerto seguro desde la perspectiva de los ciudadanos de la UE y las empresas establecidas en la UE de 27 de noviembre de 2013, COM(2013) 847 final, 20, 22). Más allá no se ha ido hasta ahora.

169 Con otro punto de vista SCHMAHL, «Rechtsschutz» (n. $\left.{ }^{\circ} 152\right), 226$; D.-K. Kipker/F. Voskamp, «PRISM und staatliche Schutzpflichten — ein politisches Märchen?», RDV 2014, 84 (86). 
sienten las propias empresas norteamericanas ${ }^{170}$, que no solo muestran periódicamente su indignación por el hecho de que las autoridades constantemente les reclaman datos ${ }^{171}$, sino que incluso combaten judicialmente estas peticiones con gran atención mediática, aunque escaso éxito ${ }^{172}$. En el nuevo mundo de los derechos fundamentales, las demandas se interponen no solo para quitar clientes, sino también para retenerlos o volver a ganarlos.

Los gobiernos europeos, por diversas razones, han sido hasta ahora cautos en su reacción ante la vigilancia de la NSA. Están políticamente vinculados a los Estados Unidos; además se supone que los servicios secretos europeos se han procurado a través de la NSA datos que ellos mismos no están autorizados a obtener ${ }^{173}$. Sin embargo, el intercambio de información tampoco sería un problema que afectara al deber de protección de los derechos fundamentales ${ }^{174}$; recabar tales datos supone más bien una injerencia directa en el derecho a la vida privada y la protección de datos, y no podría justificarse si no existe previsión legal que lo prevea $^{175}$.

En el ámbito de los deberes estatales de protección queda la propuesta de descentralizar las infraestructuras de internet, en especial creando en Europa no-

170 Esta preocupación podría ser realista: se asume en relación con el escándalo NSA que la industria estadounidense relativa a la nube ha padecido una pérdida de confianza, por lo que se estima que en los próximos tres años perderá entre el diez y el veinte por ciento de mercado en el extranjero, lo que supondrá un perjuicio entre los 21.500 y los 35.000 millones de dólares: The Information Technology \& InNOvaTION FOundation, How Much Will PRISM Cost the U.S. Cloud Computing Industry?, 2013, 3 y ss., www.itif. org/publications/how-much-will-prism-cost-us-cloud-computing-industry (31.10.2014).

171 Los principales prestadores del servicio de internet en Estados Unidos pidieron primero en una carta abierta que se limitase el espionaje estatal y que se pudiese dar a conocer con qué periodicidad y para qué fines el Gobierno iba a solicitar información sobre los usarios («US-Internetfirmen fordern Grenzen für Überwachung», ZEIT ONLINE, 9.12.2014). Después de negociar durante meses, las empresas prestadoras del servicio de internet fueron autorizadas a publicar cifras detalladas sobre el espionaje en internet ( US-Regierung lässt Technikindustrie ein bisschen Freiheit», Süddeutsche.de, 28.1.2014), lo que desde entonces está ocurriendo periódicamente (vése la primera estadística publicada por Apple images.apple.com/pr/pdf/ 140127upd_nat_sec_and_law_enf_orders.pdf, 31.10.2014). En cualquier caso, las cifras han de publicarse en referencia a grandes periodos de tiempo y de manera escalonada, lo que limita su potencial informativo ( $\mathrm{Ge}$ heimdienste griffen auf Zehntausende Online-Accounts zu», Süddeutsche.de, 4.2.2014). Respecto a la actitud crítica de las empresas servidoras de internet frente al espionaje véase WEICHERT, «Globaler Kampf» (n. $\left.{ }^{\circ} 156\right), 128$.

172 Véase por ejemplo «Verfahren in New York: Microsoft und Co. wollen Cloud-Daten vor US-Zugriff schützen», SPIEGEL ONLINE, 17.6.2014; «US-Internetkonzerne müssen in Europa gespeicherte Daten herausgeben», ZEIT ONLINE, 31.7.2014; "Judge may hold Microsoft in contempt after refusal to hand over foreign data», theguardian.com, 1.9.2014. Apple ha publicitado recientemente que, a diferencia de sus competidores, ya no puede acceder a los datos de sus iPhones y iPads y que por tanto ya no puede ser obligada a dar datos a la policía, «Apple ärgert die Polizei», ZEIT ONLINE, 18.9.2014.

173 Por ejemplo J. Borger, «GCHQ and European spy agencies worked together on mass surveillance», theguardian.com, 1.11.2013; «Vom Opfer zum Täter?», faz.net, 2.11.2013, «EU verschleierte die NSAAffäre», Die Presse, 12.9.2014.

174 Ewer/Thienel NSA-Datenskandal (n. ${ }^{\circ}$ 150), 35; H.-J. PAPIER, «Gutachterliche Stellungnahme» (n. $\left.{ }^{\circ} 152\right), 8$; SzCZEKALla, «Sicherung» (n. $\left.{ }^{\circ} 152\right), 1111$.

175 No se sabe aún si realmente existió tal intercambio, pese a los muchos esfuerzos y procesos, véase para Alemania SzCZEKALlA, «Sicherung» (n. $\left.{ }^{\circ} 152\right), 111$. 
dos de intercambio de datos, con atención singular para el servicio en la nube ${ }^{176}$; o también la de exigir a los prestadores del servicio de internet que utilicen un cifrado de datos pensando en los usuarios ${ }^{177}$. Ya es hora de que esto último se lleve a la práctica, y también parece obvia la necesidad de fortalecer las infraestructuras europeas. Pero deberíamos ser conscientes de que esto significaría asegurar los datos europeos solo frente al acceso por parte de la NSA; los servicios secretos locales podrían obtenerlos con mayor facilidad. Y tampoco cabe dar por sentado que nuestros datos estén más seguros precisamente en manos de aquellos Estados que ejercen sobre nosotros un poder coactivo inmediato ${ }^{178}$.

176 Véase por ejemplo A. Dix, «Grundrechtsschutz durch informationelle Gewaltenteilung», FS Kutscha, 2013, 95 (103 y ss.); HofFMANN-Riem, «Stellungnahme» (n. $\left.{ }^{\circ} 152\right), 18$; también la posición de S. GAYCKEN $(3,6)$ y M. WAIDNER (2, 32 y ss., 41 y ss.) en la Comisión de investigación sobre la NSA, que se encuentran en www.bundestag.de/bundestag/ausschuesse18/ua/1 untersuchungsausschuss/-/280848. Podría ser de gran ayuda en esta descentralización que vayan en la misma dirección los intereses de la política (independencia), de la economía (una mejor posición competitiva para las empresas europeas prestadoras del servicio de internet) y del ciudadano (protección de la privacidad): T. WeicherT, «Globaler Kampf» (n. ${ }^{\circ}$ 156), 131, 133.

177 Por ejemplo la decisión de la Conferencia número 86 de autoridades de protección de datos personales de la Federación y los Länder de 1 y 2 de octubre de 2013, «Sichere elektronische Kommunikation gewährleisten — Ende-zu-Ende-Verschlüsselung einsetzen und weiterentwickeln», DuD 2013, 802 (803); GAYCKEN, «Stellungnahme» (n. ${ }^{\circ}$ 176), 3, 6; WAIDNER, «Stellungnahme» (n. $\left.{ }^{\circ} 176\right)$, 39 y ss.; la codificación de los contenidos de la comunicación ciertamente no protege de la muy rentable explotación de los metadatos: M. Kutscha, «Offene Fragen zum Überwachungs-GAU», vorgänge 2013, 89 (95). Para ello tendrían que desarrollarse además servicios ampliamente disponibles que proporcionaran anonimato, WAIDNER, «Stellungnahme» (n. $\left.{ }^{\circ} 176\right), 29$ y ss., que en 45 y ss., como también GAYCKEN, «Stellungnahme» (n. $\left.{ }^{\circ} 176\right), 7$ y ss., recomendó otras medidas de seguridad para internet.

178 Tampoco está claro que los servicios secretos europeos fueran en sustancia más prudentes que la NSA; una comparación jurídica muestra que los servicios secretos americanos, británicos y alemanes se conducen de forma similar en aspectos centrales: espían comunicaciones exteriores de manera mucho más intensa que las nacionales y con una vaga habilitación. Primero se recolectan todas las comunicaciones, solo luego se filtra la comunicación nacional y finalmente se cancela, pero solo si es irrelevante para explicar la exterior. En los tres Estados, el control sobre los servicios secretos es poco efectivo, en especial se realiza casi siempre en secreto, por lo que las ilegalidades no suelen salir a la luz, véase S. HeumanN/B. ScOTT, «Rechtsrahmen für geheimdienstliche Überwachung im Internet: USA, Großbritannien und Deutschland im Vergleich», en M. Beckedahl/A. Meister (dir.), Überwachtes Netz, 2013, 149. M. B̈̈CKER, «Erhebung, Bevorratung und Übermittlung von Telekommunikationsdaten durch die Nachrichtendienste des Bundes», en la Comisión de investigación del asunto NSA el 22.5.2014, 23 (www.bundestag.de/bundestag/ausschuesse18/ua/1 untersuchungsausschuss/-/280848, 31.10.2014), señaló incluso que, en la práctica, la recolección de datos por parte del servicio secreto alemán «en absoluto se queda por detrás de los procedimientos de los servicios de información extranjeros», tomando como fundamento para las escuchas en el extranjero (de acuerdo con el Gobierno Federal, aunque sea equivocado desde el punto de vista constitucional) la simple atribución de tareas del § 3.2.1 BNDG. También considera cuestionable desde el punto de vista jurídico-constitucional el espionaje en el extranjero del servicio secreto alemán B. Huber, «Die strategische Rasterfahndung des Bundesnachrichtendienstes - Eingriffsbefugnisse und Regelungsdefizite», NJW 2013, 2572 (2574, 2576 y ss.). Como señala finalmente MARgulies, «NSA» (n. $\left.{ }^{\circ} 159\right)$, 2158 y ss., tampoco la protección de la vida privada por el CEDH es netamente superior a la de los Estados Unidos. La argumentación jurídico-constitucional en los Estados Unidos y Alemania se parece, "pese a las diversas culturas en materia de protección de datos», tal y como muestran K. F. GärdiTz/C.-F. STUCKENBERG, «Vorratsdatenspeicherung à l'américaine — Zur Verfassungsmäßigkeit der Sammlung von Telefonverbindungsdaten durch die NSA», JZ 2014, 209 (219). Si los servicios secretos europeos no han espiado tan intensamente como el grupo de los «Five eyes», ello no necesariamente se debería por tanto a su superioridad en materia de Estado de Derecho; también podría ser simplemente resultado de su retraso tecnológico. 
Frente a esta amenaza externa solo cabe, pues, más autoprotección y también más autocontrol: no podemos ya escaparnos de internet ${ }^{179}$, pero también hay cosas a las que podemos renunciar. No necesitamos una comunicación permanente, no todo debe contarse y, especialmente, no es preciso contárselo todo a todos sin descanso ${ }^{180}$.

¿Qué podemos aprender del affaire NSA? Quien quiera controlar el mundo entero necesita ayuda en todo el mundo; y quien necesita tantos ayudantes genera también puntos de apoyo para la protección de los derechos humanos.

Los ayudantes particulares son muy útiles al Estado en la medida que disponen de capacidades que él no puede desarrollar. Pero si tales ayudantes tienen también actividad comercial, entonces desplegarán una doble lealtad. De modo que no se ha de descartar que el prestador de servicios de internet se distancie a medio plazo del Estado, reforzando sus vínculos con los usuarios.

El escándalo NSA todavía muestra algo más: no todo lo que parece relativo al deber de protección es realmente un problema de protección ${ }^{181}$. El ciudadano tampoco tiene que esperar siempre a que le protejan; en algunos casos puede evitar ciertas intromisiones, y también debería protegerse de sí mismo.

\section{V. ¿UN NUEVO MUNDO LLENO DE PELIGROS?}

Es el momento de concluir con un resumen: en el nuevo mundo lleno de peligros, las tres premisas del concepto clásico de derechos fundamentales están puestas en cuestión. La bipolaridad de la relación de derechos fundamentales -a un lado el ciudadano, a otro el Estado — ha pasado, en primer lugar, a ser una pluralidad multipolar, de suerte que junto al Estado aparecen bajo el foco, como sujetos de una posible injerencia sobre los derechos fundamentales, híbridos privado-estatales, poderosos actores privados y figuras difusas como las comunidades de internet. Esta ampliación de los sujetos que intervienen sobre los derechos fundamentales se corresponde, en segundo término, con la extensión y descentralización de los instrumentos de poder; que, como antes, se sigue ejerciendo a través de la coacción, pero también con el dinero y, sobre todo, mediante la información. En tercer lugar, se han diversificado los lugares desde los que producen injerencias en los derechos fundamentales: el escenario es hoy el mundo entero.

$179 \mathrm{La}$ «vida como un Robinson antidigital» resulta, tal y como señala certeramente HoFFMANN-RIEM, «Freiheitsschutz» (n. $\left.{ }^{\circ} 150\right)$, 54, una «alternativa no realista».

180 Se ha abogado por la autoprotección en materia de datos, en especial limitando la disponibilidad y entrega de datos a lo estrictamente indispensable, véase por ejemplo T. WEICHERT, «PRISM, Tempora, Snowden: Analysen und Perspektiven», in: Beckedahl/Meister (n. $\left.{ }^{\circ} 178\right), 179$ (184 y ss.).

181 A menudo, la intervención sobre un derecho fundamental se analiza erróneamente y en perjuicio de la garantía del derecho bajo la perspectiva de los deberes de protección, como ha mostrado en general SzCZEKALLA, Schutzpfichten (n. $\left.{ }^{\circ} 31\right), 438$ y ss. 
Este triple fenómeno dificulta que el ciudadano haga valer sus derechos. Pero la sociedad civil ha desarrollo sus propias estrategias de defensa. Para protegerse frente a los poderosos sujetos que vulneran los derechos fundamentales lleva a escena, cada vez más, a activistas organizados que luchan por los derechos fundamentales de forma inteligente y comprometida. Son onegés y también luchadores solitarios como el valiente Max Schrems, que litiga contra Facebook desde hace años y con relativo éxito ${ }^{182}$.

La sociedad civil crea sus propios «espías» frente al ejercicio opaco del poder: wistleblower (denunciantes), periodistas de investigación y de nuevo oenegés que informan a la opinión pública mundial de la vulneración de derechos humanos e impulsan ciertas discusiones, usando a su vez, por tanto, el poder de la información. Algunos de ellos son simplemente espías que han cambiado de bando, como Edward Snowden ${ }^{183}$ o Caspar Bowen, antaño trabajador de Microsoft y hoy luchador enérgico en favor de la protección de datos ${ }^{184}$. También estas figuras desempeñan un papel creciente en el drama de los derechos fundamentales.

En ocasiones, incluso el público irrumpe en la escena, porque ya no acepta mirar con los brazos cruzados las vulneraciones de derechos humanos y aspira a frenarlas mediante protestas. Se trata de consumidores que más allá de cualquier frontera boicotean conglomerados multinacionales, sirviéndose del poder del dinero y aprovechando el talón de Aquilles de las empresas, que reside en su reputación.

La obra de los derechos fundamentales no es, en definitiva, un musical estéril, producido una vez y escenificado siempre del mismo modo en todo el mundo; se parece más a una típica representación de Bayreuth, sobre la que se sigue siempre trabajando, una y otra vez. En esta obra, el Estado todavía asume un papel importante, pero ya no el principal. Tampoco lleva ya la dirección. Hoy, el drama de los derechos fundamentales carece de una gran puesta en escena; especialmente en contextos transfronterizos, se convierte más bien en una obra de teatro improvisado. Con todo, el tema general de esta pieza está más claro: no se trata

182 Las actuaciones de su plataforma «Europe versus Facebook» están documentadas en www.europev-facebook.org/DE/de.html; ahí se encuentra también el procedimiento contra Irlanda señalado en la nota 161 .

183 El caso Snowden muestra también claramente qué riesgos asumen los denunciantes, pues la gente admite «la traición», pero no a «los traidores». Así, Snowden, tras su revelaciones, fue enseguida desacreditado en los medios (los detalles en GREENWALD, Überwachung [Fn. 153], 297 y ss.), despedido por su empleador y perseguido penalmente por los Estados Unidos. Frente a esa persecución no encontró protección en los Estados occidentales (algo criticado muy a menudo, por ejemplo véase WEICHERT, «PRISM» [n. ${ }^{\circ} 180$ ], 183 y ss.), sino primero en China y luego en Rusia, donde todavía vive año y medio después de sus revelaciones. No le repara el hecho de que haya recibido muchos premios por su coraje, entre ellos el nobel alternativo (Right Livelihood Award). Con razón se reclaman leyes de protección más eficaces para los denunciantes, por ejemplo D. Deiseroth, «Whistleblowing und ziviler Ungehorsam im demokratischen Verfassungsstaat», Neue Gesellschaft Frankfurter Hefte 2014, Heft 1-2, 4; WeICHERT, «Globaler Kampf» (n. ${ }^{\circ}$ 156), 131.

184 En detalle K. Kohlenberg/Y. Musharbash/W. Wiedmann-Schmidt, «Sie wissen, wer du bist», ZEIT ONLINE, 2.6.2014 
tanto del domino del Estado sobre las personas como de las relaciones de dominio entre personas.

En esta obra, la ciencia jurídica ocupa el lugar de la tribuna de prensa especializada. En virtud de su capacidad de observación y de sus instrumentos de análisis vierte una aguda mirada sobre las circunstancias sociales y por ello también puede recomendar el mejor modo de poner la obra en escena. Pero hay tres reglas que siguen siendo válidas. Primera, el enemigo del ciudadano puede no ser el Estado, pero debe tener rostro y resultar accesible, pues en otro caso no será posible dirigirse contra él; en ello consiste la verdad nuclear de la primera premisa. Segunda, el poder no se ejerce solo mediante la coacción, pero el ciudadano ha de saber si se gobierna y con qué medios, por eso deben iluminarse las acciones secretas; es la verdad que permanece en la segunda premisa. La tercera premisa, conforme a la cual el Estado domina en su territorio, hace tiempo que fue falsada; los problemas que surgen en las intervenciones transfronterizas requieren ingenio y capacidad de experimentación. Estas dos cualidades, por lo demás, quizá resultan imprescindibles para dominar el escenario en el que hoy nos encontramos.

$$
* * *
$$

TITLE: Ensuring standards of human and fundamental rights in order to face new threats generated by private and foreign actors

ABSTRACT: The classical conception of fundamental rights responds to three premises: the relationship of fundamental rights is bipolar, between state and citizen; the state monopolizes the force and against this force citizens are protected by the fundamental rights; the state holds the force in his own territory. Today, the three premises are being questioned. The state is not the only one who can interfere on fundamental rights, but also bybrid private-state subjects, private actors and diffuse powerful figures such as Internet communities. The power instruments also extend and decentralized themselves, and include not only coercion, but also money and power of information. Third, the scene of fundamental rights is the whole world. All of this binder the effectiveness of fundamental rights, but three rules are still valid. Although the enemy of citizens would not be the state, he must have a face and be accessible, since otherwise it would not be possible to go against bim. The power is not exercised only through coercion, but the citizen has to know whether it is subject to control and how it is exercised, so the scope of secrets must be reduced. Finally, cross-border actions can only deal with cleverness and experimentation, not only with the law but also through the engagement of the civil society.

RESUMEN: La concepción clásica de los derechos fundamentales responde a tres premisas: la relación de los derechos fundamentales es bipolar, entre Estado y ciudadano; el Estado monopoliza la fuerza frente a la que nos protegen los derechos fundamentales; el Estado la ejerce en su propio territorio. Hoy, las tres premisas están puestas en cuestión. Junto al Estado aparecen, como sujetos de una posible injerencia sobre los derechos fundamentales, hibridos privado-estatales, poderosos actores privados y figuras difusas como las comunidades de internet. Los instrumentos de poder también se extienden y descentralizan, y junto a la coacción bay que tener en cuenta el dinero y el poder de la información. En tercer lugar, el escenario de los derechos fundamentales es el mundo entero. Todo ello dificulta la vigencia de los derechos fundamentales, pero tres reglas siguen siendo válidas. El enemigo del ciudadano puede no ser el Estado, pero debe tener rostro y resultar accesible, pues en otro caso no será posible dirigirse contra él. El poder no se ejerce solo mediante la coacción, pero el ciudadano ha de saber si está sujeto a dominio y con qué medios se ejerce el mismo, por lo que debe reducirse el ámbito de lo secreto. Finalmente, las actuaciones transfronterizas sólo pueden enfrentarse con ingenio y capacidad de experimentación, no solo mediante el derecho, sino también mediante la implicación de la sociedad civil. 
KEY WORDS: Human Rights, Fundamental Rights, horizontal effect, extraterritorial effect, political power, economic power, power of information and comunication, judicial guarantees, civil society.

Palabras Clave: Derechos humanos, derechos fundamentales, eficacia horizontal, eficacia extraterritorial, poder político, poder económico, poder de la información y la comunicación, garantías judiciales, sociedad civil.

FECHA DE RECEPCIÓN: 03.03.2015

FECHA DE ACEPTACIÓN: 29.07.2015 